\title{
Satellite observations of daytime and nighttime ozone in the mesosphere and lower thermosphere
}

\author{
M. Kaufmann, ${ }^{1,2}$ O. A. Gusev, ${ }^{1}$ K. U. Grossmann, ${ }^{1}$ F. J. Martín-Torres, ${ }^{3}$ D. R. Marsh, ${ }^{4}$ \\ and A. A. Kutepov ${ }^{5}$ \\ Received 26 July 2002; revised 25 October 2002; accepted 16 December 2002; published 7 May 2003.
}

[1] The global distribution of mesospheric and lower thermospheric ozone $9.6 \mu \mathrm{m}$ infrared emissions was measured by the Cryogenic Infrared Spectrometers and Telescopes for the Atmosphere (CRISTA) experiment during two Space Shuttle missions in November 1994 and August 1997. The radiances measured by CRISTA have been inverted to $\mathrm{O}_{3}$ number densities in the $50-95 \mathrm{~km}$ range by using a nonlocal thermodynamic equilibrium model. A detailed sensitivity study of retrieved $\mathrm{O}_{3}$ number densities has been carried out. The ozone abundance profiles show volume mixing ratios of $1-2$ ppmv at the stratopause, $0.5 \mathrm{ppmv}$ or less around $80 \mathrm{~km}$, and typically $1 \mathrm{ppmv}$ during daytime and 10 ppmv during nighttime at the secondary maximum. The agreement with other experiments is typically better than $25 \%$. The global distribution of upper mesospheric ozone shows significant latitudinal gradients and an enhancement in the equatorial upper mesosphere. At the polar night terminator a third ozone maximum is observed. Three-dimensional model results indicate that the latitudinal gradients are significantly influenced by solar tides. INDEX TERMS: 0340 Atmospheric Composition and Structure: Middle atmosphere - composition and chemistry; 3332 Meteorology and Atmospheric Dynamics: Mesospheric dynamics; 3360 Meteorology and Atmospheric Dynamics: Remote sensing; 3394 Meteorology and Atmospheric Dynamics: Instruments and techniques; KEYWORDS: mesosphere, ozone, CRISTA, lower thermosphere, ROSE, non-LTE

Citation: Kaufmann, M., O. A. Gusev, K. U. Grossmann, F. J. Martín-Torres, D. R. Marsh, and A. A. Kutepov, Satellite observations of daytime and nighttime ozone in the mesosphere and lower thermosphere, J. Geophys. Res., 108(D9), 4272, doi:10.1029/2002JD002800, 2003.

\section{Introduction}

[2] Ozone is a key factor in the structure and dynamics of the earth's atmosphere [London, 1980]. The absorption of solar ultraviolet (UV) radiation by ozone constitutes the essential source of heat in the middle atmosphere [Brasseur and Solomon, 1986] and contributes significantly to the increase in temperature with increasing altitude forming the stratosphere. A complete description of the thermal structure and photochemistry of the middle atmosphere is not possible unless the ozone abundance is well characterized.

[3] The typical vertical profile of the ozone volume mixing ratio shows two distinct maxima, one in the stratosphere at $35 \mathrm{~km}$ and one near the mesopause. The secondary maximum was first detected by Evans and Llewellyn [1972]

\footnotetext{
${ }^{1}$ Department of Physics, University of Wuppertal, Wuppertal, Germany.

${ }^{2}$ Now at Research Center Jülich, Jülich, Germany.

${ }^{3}$ NASA Langley Research Center, Hampton, Virginia, USA.

${ }^{4}$ National Center for Atmospheric Research, Boulder, Colorado, USA.

${ }^{5}$ Max Planck Institute for Extraterrestrial Physics-Institute for Astronomy and Astrophysics, University of Munich, Munich, Germany.

Copyright 2003 by the American Geophysical Union. 0148-0227/03/2002JD002800
}

in daytime ozone and by Hays and Roble [1973] during night and was explained by several theoretical model results [e.g., Shimazaki and Laird, 1970; Hunt, 1966; Keneshea et al., 1979; Allen et al., 1984; Rodrigo et al., 1981, 1986]. In addition to the simple photochemical scheme $\left(\mathrm{O}_{2}+\mathrm{h} \nu \rightarrow\right.$ $\mathrm{O}+\mathrm{O} ; \mathrm{O}+\mathrm{O}_{2}+\mathrm{M} \rightarrow \mathrm{O}_{3}+\mathrm{M}$ ) [Chapman, 1930], chemical reactions with active hydrogen and molecular as well as turbulent mass transport play an important role in the explanation of the secondary ozone maximum. Typical ozone mixing ratios are $2 \mathrm{ppmv}$ at the stratopause, 0.5 ppmv below the secondary maximum and $1 \mathrm{ppmv}$ (day) or 10 ppmv (night) at the secondary maximum.

[4] Ozone measurements in the mesosphere and in the lower thermosphere were carried out by a variety of techniques. An overview of early satellite experiments to measure ozone is given by Hays and Roble [1973] and Krueger et al. [1980]. The technique mostly used to derive ozone in the middle and upper mesosphere is UV absorption spectroscopy with the sun or stars as sources of UV light [Roble and Hays, 1974; Riegler et al., 1976; Weeks et al., 1978; Fussen et al., 2000]. In addition to the UV occultation, the absorption of infrared radiation has also been used to infer ozone profiles in the mesosphere [Gunson et al., 1990; Brühl et al., 1996]. Another technique is the detection of the molecular oxygen 
dayglow emissions, which arise in part from processes related to the photolysis of ozone: the $\mathrm{O}_{2}\left({ }^{1} \Sigma \rightarrow{ }^{3} \Sigma\right)(0,0)$ band at $762 \mathrm{~nm}$ [López-González et al., 1992a, 1992b; Marsh et al., 2002; Mlynczak et al., 2001], the (0,1) band at $864 \mathrm{~nm}$ [Noxon, 1975] and the $\mathrm{O}_{2}\left({ }^{1} \Delta \rightarrow{ }^{3} \Sigma\right)$ band at $1.27 \mu \mathrm{m}$ [Llewellyn and Witt, 1977; Weeks et al., 1978; Thomas et al., 1984; Evans et al., 1988; Mlynczak et al., 2001]. Ozone emissions in the microwave region are used by some ground- and space-based instruments to infer the ozone density in the mesosphere. Ground-based microwave spectrometry was applied by Wilson and Schwartz [1981], Zommerfelds et al. [1989], Connor et al. [1994] and references cited therein. Spaceborne measurements of ozone microwave emissions were carried out by Froidevaux et al. [1996] and Bevilacqua et al. [1996]. Ozone in the upper mesosphere and lower thermosphere (UMLT) was also measured by rocket borne mass spectrometers [Trinks, 1975] and by the analysis of the duration distribution of overdense radio meteor echoes [Jones et al., 1990; Cevolani et al., 1999].

[5] Infrared emission measurements overcome the limitations in the local time coverage of solar occultation and dayglow measurements and their altitude resolution is significantly higher in comparison with microwave data. Several rocket borne measurements of mesospheric ozone infrared emissions have been performed [e.g., Rawlins et al., 1985; Green et al., 1986; Adler-Golden and Smith, 1990; Adler-Golden et al., 1990; Grossmann and Vollmann, 1997]. Global upper mesospheric ozone infrared emission measurements have been analyzed by Zhou et al. [1998] and Mill et al. [1994].

[6] The main difficulty of deriving ozone from its infrared emissions is to model the occupancy of its vibrational states, which are in nonlocal thermodynamic equilibrium (non-LTE) [Rawlins et al., 1985; Solomon et al., 1986; Mlynczak and Drayson, 1990a, 1990b; Adler-Golden et al., 1992; Manuilova and Shved, 1992; Manuilova et al., 1998]. There are basically two reasons for the breakdown of LTE for the ozone $\nu_{3}$ vibrational mode $(9.6 \mu \mathrm{m})$ in the UMLT: Vibrationally excited molecules are produced in the recombination reaction $\left(\mathrm{O}_{2}+\mathrm{O} \rightarrow \mathrm{O}_{3}^{*}\right)$ and by absorption of radiation emitted from the lower and much warmer atmosphere while the collision frequency and the quenching rates are not large enough to restore LTE to these levels. Most models suggest that the first excited states of the $v_{1}, v_{2}$ and $\nu_{3}$ modes are mainly determined by radiative absorption and thermal collisions and only to a lesser extent by the recombination reaction [e.g., Manuilova and Shved, 1992]. Details are given below.

\section{CRISTA Observations}

[7] CRISTA was a limb-scanning satellite experiment [Offermann et al., 1999; Riese et al., 1999; Grossmann et al., 2002] and was flown twice aboard the ASTROnomical Shuttle PAllet Satellite (ASTRO-SPAS) free-flying platform on the Space Shuttle missions STS-66 (1994) and STS-85 (1997). The orbit altitude was $300 \mathrm{~km}$, and the orbit inclination was $57^{\circ}$ during the two missions. Atmospheric limb measurements were taken during two periods (November 4-12, 1994, and August 8-16, 1997). Both CRISTA flights took place near the minimum of the solar cycle and

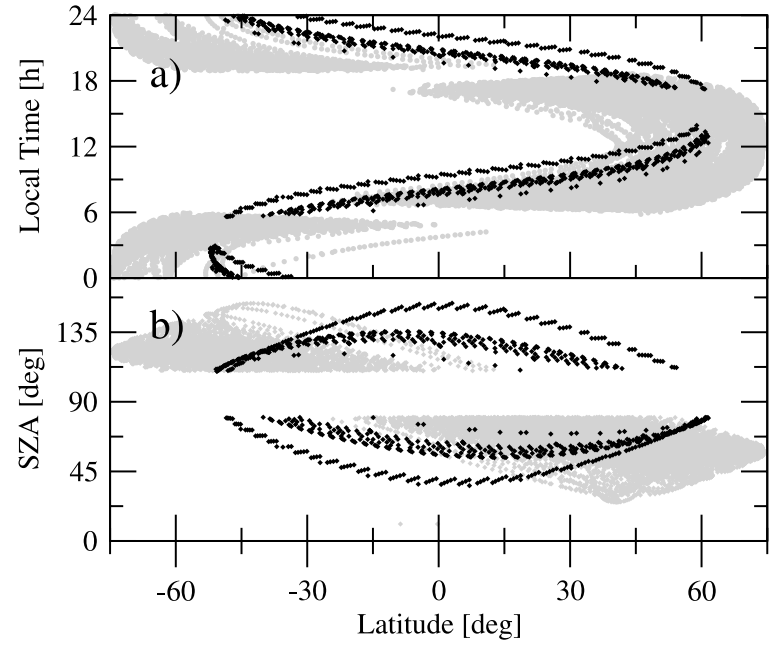

Figure 1. (a) Local time- latitude coverage of the mesospheric data for CRISTA-1 (November 8-11 1994; black diamonds) and CRISTA-2 (August 8-16 1997; shaded area). (b) solar zenith angle- latitude coverage.

mostly under geomagnetically quiet conditions. CRISTA made global measurements of trace-gas thermal emissions in the $4-71 \mu \mathrm{m}$ region with a high horizontal and vertical resolution and with a medium spectral resolution. The radiance was analyzed by means of Ebert-Fastie grating spectrometers in 13 different wavelength intervals. The CRISTA $9.6 \mu \mathrm{m}$ channels cover the wavenumber interval $979-1122 \mathrm{~cm}^{-1}$. The spectral resolution $(\lambda / \Delta \lambda)$ is 390 and the wavenumber increment between two subsequent spectral sampling points is about $0.67 \mathrm{~cm}^{-1}$. The noise equivalent spectral radiance (NESR) is in the order of $1.5 \cdot 10^{-10}$ $\mathrm{W} /\left(\mathrm{cm}^{2} \mathrm{sr} \mathrm{cm}^{-1}\right)$ for all CRISTA $9.6 \mu \mathrm{m}$ channels used in the retrieval. Typical Signal/Noise ratios of the 1010-1065 $\mathrm{cm}^{-1}$ integrated radiances are 1 and 8 for daytime and 10 and 60 for nighttime at $100 \mathrm{~km}$ and $90 \mathrm{~km}$, respectively.

[8] Altitude profiles are sampled with a vertical increment of $2.1-2.6 \mathrm{~km}$ in the mesosphere and lower thermosphere (MLT). The width of the vertical field of view is about $1.5 \mathrm{~km}$. To obtain a high horizontal resolution, three telescopes are used to sound the atmosphere simultaneously. During the CRISTA-2 mission $9.6 \mu \mathrm{m}$ measurements in the MLT were performed by all three telescopes, but during CRISTA-1 only one of the telescopes was used in this altitude region. Figure 1 shows the solar zenith angles (SZA)- and local time (LT)- latitude coverage for both CRISTA missions. For a given latitude, observations are made at two different local solar times and at different solar zenith angles. The limb observation geometry together with the attitude capabilities of the ASTRO-SPAS satellite allowed atmospheric volumes to be scanned beyond the latitudes covered by the $57^{\circ}$ orbit [Grossmann et al., 2002]. Daytime measurements $\left(\mathrm{SZA}<80^{\circ}\right)$ cover $49^{\circ} \mathrm{S}$ to $61^{\circ} \mathrm{N}$ for CRISTA-1 and $18^{\circ} \mathrm{S}$ to $73^{\circ} \mathrm{N}$ for CRISTA-2 and nighttime measurements $\left(\mathrm{SZA}>110^{\circ}\right.$ ) cover $52^{\circ} \mathrm{S}$ to $60^{\circ} \mathrm{N}$ for CRISTA- 1 and $73^{\circ} \mathrm{S}$ to $16^{\circ} \mathrm{N}$ for CRISTA-2.

[9] At altitudes above $55 \mathrm{~km}$ the ozone $9.6 \mu \mathrm{m}$ limb radiance shows a strong diurnal variation [Solomon et al., 1986]. Figure 2 compares day and nighttime radiance profiles at two different latitudes, respectively. The thin 


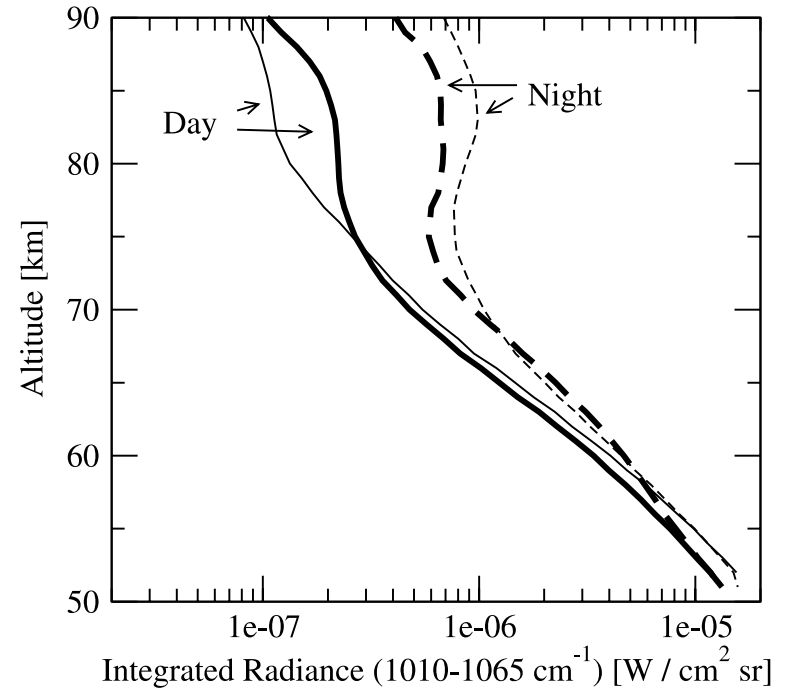

Figure 2. Day and nighttime radiance profiles for CRISTA-2 (August $8-16$ 1997) at $0^{\circ} \pm 5^{\circ}$ latitude (thin curves) and $50^{\circ} \pm 5^{\circ} \mathrm{N}$ (thick curves). The average local time for the daytime profiles is $8 \mathrm{~h} / 11 \mathrm{~h}$ (thin/thick curve) and $21 \mathrm{~h} / 18 \mathrm{~h}$ for the nighttime profile. The random error is $10^{-8} \mathrm{~W} /\left(\mathrm{cm}^{2} \mathrm{sr}\right)$.

(thick) curves are mean intensity distributions at $0^{\circ} \pm 5^{\circ}$ $\left(50^{\circ} \pm 5^{\circ}\right)$ latitude; the average local time for the daytime profile is $8 \mathrm{~h}(11 \mathrm{~h})$ and $21 \mathrm{~h}(18 \mathrm{~h})$ for the nighttime profile. Up to $60 \mathrm{~km}$ day and night profiles agree within 30\%; at 70 $\mathrm{km}$ the nighttime profile is a factor of 2 higher. Above 70 $\mathrm{km}$ this ratio is latitude-dependent increasing to a factor of 4 at $90 \mathrm{~km}$ for the mid-latitude profiles and up to a factor of 9 for the equatorial profiles. This variation is primarily due to the diurnal variation of the ozone concentration and only to a lesser extent to the day/night difference in the excitation mechanisms [Mlynczak and Drayson, 1990a].

\section{Non-LTE $\mathrm{O}_{3}$ Limb Radiances Modeling}

[10] The modeling of the vibrational excitation separates into two major parts: (1) the solution of the radiative transfer equation, which relates the local radiation field to the excitation of ozone in the entire atmosphere and (2) the coupling of all possible vibrational states assuming steady state (statistical equilibrium equations). Both parts are calculated very efficiently with the non-LTE model of Kutepov et al. [1998]. The multilevel non-LTE problem is solved using the Accelerated Lambda Iteration (ALI) technique [Rybicki and Hummer, 1991] and the radiative transfer is calculated line-by-line using the Feautrier method [Rybicki and Hummer, 1991]. The non-LTE model of ozone is similar to that introduced by Manuilova et al. [1998]. It is limited to 23 vibrational levels of ozone containing up to 3 $\nu_{3}$ vibrational quanta, 3 vibrational levels of $\mathrm{O}_{2}$ and 2 vibrational levels of $\mathrm{N}_{2}$. The chosen vibrational levels are divided into groups, defined by putting together levels with similar vibrational energies having a fixed sum of $\nu_{1}+\nu_{3}$ numbers and the same $\nu_{2}$ excitation.

[11] In the model, the recombination reaction produces ozone in all vibrational modes in the group with the highest energy and relaxation is through all levels. The collisional model takes into account vibrational-translational and vibrational-vibrational transfer between ozone and $\mathrm{N}_{2}, \mathrm{O}_{2}$ and atomic oxygen as well as chemical destruction of vibrationally excited ozone by atomic oxygen. A detailed description of the individual excitation processes of the vibrational levels is given by Manuilova and Shved [1992] and Manuilova et al. [1998] (model 1).

[12] The contribution of the $\mathrm{CO}_{2}$ emissions for the radiation in the CRISTA channels is simulated with the $\mathrm{CO}_{2}$ non-LTE model described by Kaufmann et al. [2002]. The importance of the various processes on the ozone retrieval is discussed in the next section.

[13] Limb spectra measured in the $979-1120 \mathrm{~cm}^{-1}$ wavenumber interval are composed of the emissions from different bands of ozone and $\mathrm{CO}_{2}$. High resolution daytime limb radiance spectra showing the various $9-11 \mu \mathrm{m}$ bands of $\mathrm{CO}_{2}$ and $\mathrm{O}_{3}$ are published by Edwards et al. [1994] and F. J. Martín-Torres et al. (manuscript in preparation, 2002). For the calculation of the CRISTA non-LTE limb radiances we developed a fast line-by-line radiation code [Kaufmann et al., 2002]. The optical thickness of the mesosphere is low for $9.6 \mu \mathrm{m}$ limb radiance [Edwards et al., 1994] and therefore it is not necessary to account for overlap of spectral lines above $50 \mathrm{~km}$ [Mlynczak and Drayson, 1990b]. Simulated daytime limb emission spectra for various tangent heights convoluted by the instrument line shape function of CRISTA are shown in Figure 3. The calculation is for $21^{\circ} \mathrm{S}, 66^{\circ} \mathrm{W}$, November 9,1994 using a background atmosphere from the GRAM model [Justus et al., 1995] and a mean CRISTA-1 daytime ozone profile. The dominant

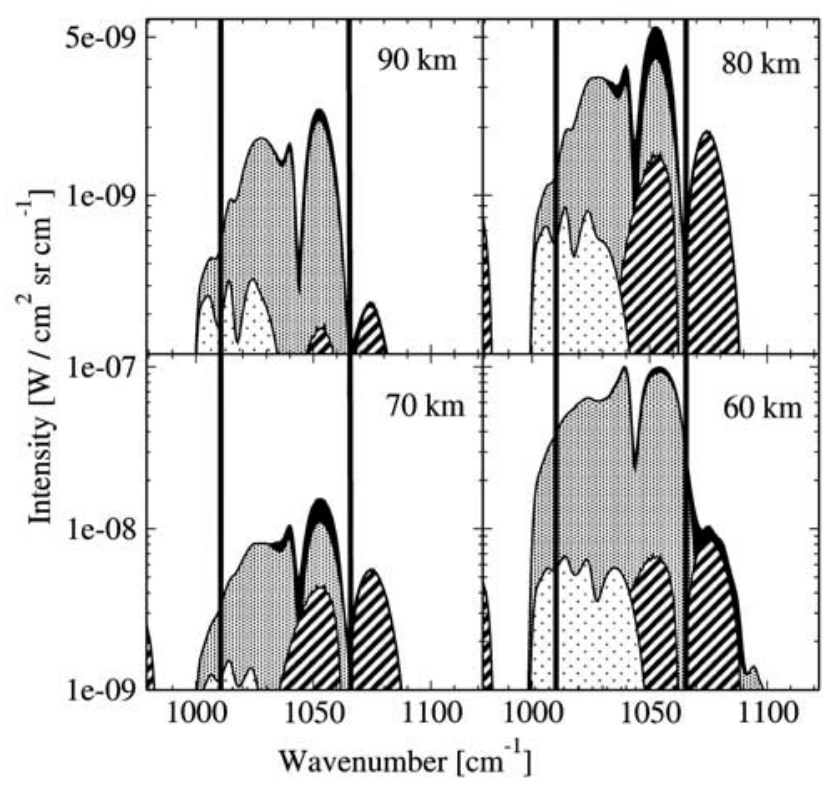

Figure 3. Simulated spectral contributions in the CRISTA $9.6 \mu \mathrm{m}$ channel $\left(21^{\circ} \mathrm{S}, 66^{\circ} \mathrm{W}\right.$, November 9, 1994) for tangent heights specified in the plot labels $(90,80,70$, and $60 \mathrm{~km}$ ). Note the different intensity scaling of the top and the bottom panel. Black: total radiance, grey: total ozone radiance, dotted: ozone hotband emissions, shaded: $\mathrm{CO}_{2}$ emissions. The vertical lines indicate the retrieval interval. 


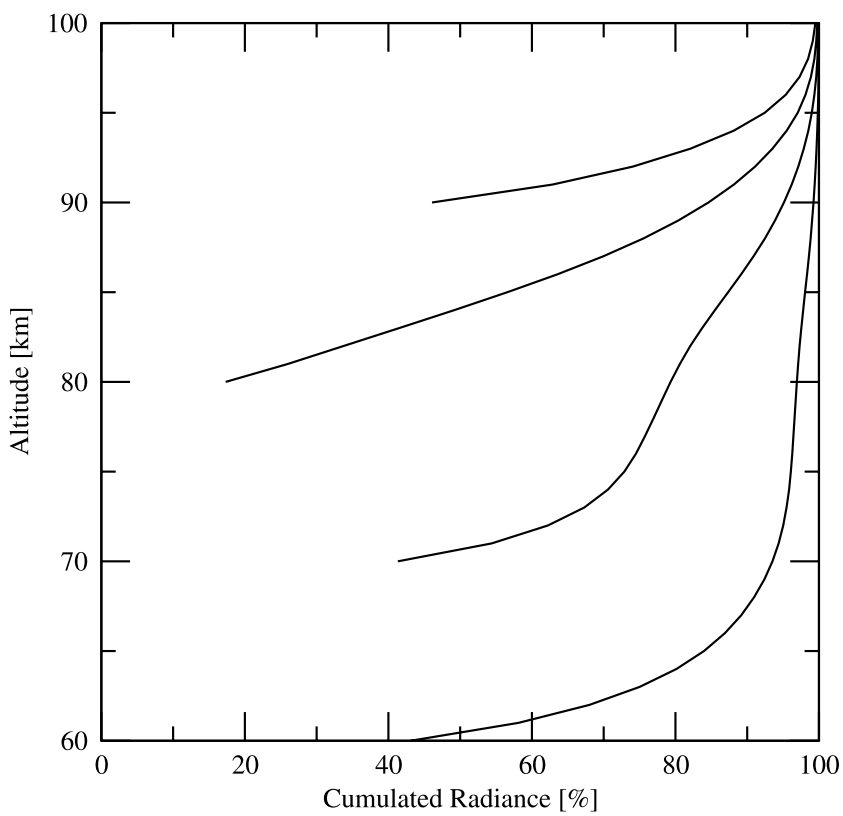

Figure 4. Portion of intensity $\left(1010-1065 \mathrm{~cm}^{-1}\right)$ which stems from the tangent layer and the atmospheric layers above. The vertical binning is $1 \mathrm{~km}$. The calculation is for $50^{\circ} \mathrm{S}, 149^{\circ} \mathrm{E}$, midnight (November 9, 1994).

spectral features are from the $\mathrm{O}_{3}$ main isotope fundamental band emission, located between 1010 and $1065 \mathrm{~cm}^{-1}$. Ozone hotband emissions, primarily the $(002-001)$ and (011-010) transitions, are visible in the long wavelength regions of the spectra, but their contribution is $10 \%$ or less for wavenumbers greater than $1010 \mathrm{~cm}^{-1}$. During daytime, radiance from the $\mathrm{CO}_{2}(00011-10002)$ solar pumped hotband give up to $40 \%$ contribution in the $1035-1090 \mathrm{~cm}^{-1}$ region between $65 \mathrm{~km}$ and $85 \mathrm{~km}$.

[14] The portion of radiance which stems from atmospheric layers close to the tangent height depends on the altitude gradient of the ozone profile and the optical thickness of the atmosphere. At $90 \mathrm{~km}$ tangent height $65 \%$ of the total radiance $\left(1010-1065 \mathrm{~cm}^{-1}\right)$ is emitted from a $2 \mathrm{~km}-$ thick layer above the tangent point (Figure 4). Since the ozone VMR drops off rapidly with decreasing altitude, the portion of intensity which comes from the tangent layer is reduced. At $80 \mathrm{~km}$ only $25 \%$ of the radiance stems from the $2 \mathrm{~km}$-thick tangent layer. Further down the altitude gradient of $\mathrm{O}_{3}$-VMR is reversed and the fraction of radiance from the tangent layer increases again.

[15] The vibrational excitation modeling and the inversion of limb radiances to ozone number densities is performed iteratively in two steps. In the first step the vibrational excitation of ozone using the non-LTE model is calculated. In the second step this excitation is frozen and the measured radiances are simulated with the forward radiance model. Ozone number densities are retrieved using the onion-peeling technique [Russell and Drayson, 1972], i.e. the retrieval steps downwards through the atmosphere, retrieving ozone at the tangent level using the radiances just from that level and values of the already retrieved products above the tangent level. No smoothing constraints for the adaption of modeled and measured radiances and no explicit usage of a priori knowledge of ozone densities is made. The altitude resolution of retrieved ozone is given by the vertical increment of two subsequent measurements, e.g., $2.1-2.6 \mathrm{~km}$.

\section{Sensitivity Study and Error Analysis for the $\mathbf{O}_{3}$ Retrieval}

[16] The retrieval of ozone densities depends on various assumptions that are made in the non-LTE modeling of the $9.6 \mu \mathrm{m} \mathrm{limb}$ radiance. In this section we will discuss the most important uncertainties in the processes affecting the vibrational excitation of ozone. The dependence of retrieved ozone on atmospheric quantities such as the kinetic temperature and the atomic oxygen density will also be discussed.

\subsection{Non-LTE Processes}

[17] The non-LTE kinetic models differ mainly in the number of states they consider, the scheme for calculating unmeasured collisional rates, the way they assume the $\mathrm{O}_{3}$ vibrational states are populated after the recombination reaction $\mathrm{O}+\mathrm{O}_{2}+\mathrm{M}$ (nascent distribution), and how they consider the removal of vibrationally excited ozone by atomic oxygen.

[18] There are four principal suggestions for the nascent distribution of vibrationally excited ozone formed in the recombination reaction: (1) $\mathrm{O}_{3}$ is produced in the $\nu_{3}$ mode, only, and the population of the various levels depends on their vibrational excitation. Rawlins et al. [1985] derived a statistical vibrational distribution which decreases with excitation. This approach was used by Mlynczak and Drayson [1990a] (Simple Single Model), Fichet et al. [1992], and Zhou et al. [1998]; (2) An "inverse Rawlins distribution" (F. J. Martín-Torres et al., manuscript in preparation, 2002), which assumes that the whole manifold of vibrational states below the energy dissociation limit are populated after recombination and favors the population of the higher vibrational states. (3) $\mathrm{O}_{3}$ is produced in all vibrational modes at the highest energy level (Adler-Golden and Smith [1990], Mlynczak and Drayson [1990a] ("energy gap" and "Adler-Golden" models), Fichet et al. [1992], and Manuilova et al. [1998]). (4) A statistical state distribution which results if the entropy change of the reaction is maximized, i.e. if all final states are equally probable [Pemberton, 1993].

[19] The importance of the nascent distribution on the vibrational temperature of daytime $\mathrm{O}_{3}(001)$ and on the change of retrieved ozone is illustrated in Figure 5. The atmospheric condition for daytime is the same as for Figure 3, the nighttime calculation is for $51^{\circ} \mathrm{S}, 14^{\circ} \mathrm{E}$. The main deviation of the $\mathrm{O}_{3}(001)$ vibrational temperature from the kinetic temperature is caused by the radiative excitation and a relatively small fraction depends on the recombination reaction only. These processes change the daytime vibrational temperature by $2 \mathrm{~K}$ at $70 \mathrm{~km}$, reaching a maximum of $8 \mathrm{~K}$ at $85 \mathrm{~km}$ and decreasing to $6 \mathrm{~K}$ at $95 \mathrm{~km}$. The retrieved ozone densities differ by $14 \%, 40 \%$ and $35 \%$, respectively.

[20] For the error analysis of retrieved ozone due to the recombination reaction the difference between case (3) and the most extreme cases (Rawlins distribution and inverse Rawlins distribution) is used. Retrieved ozone is typically 


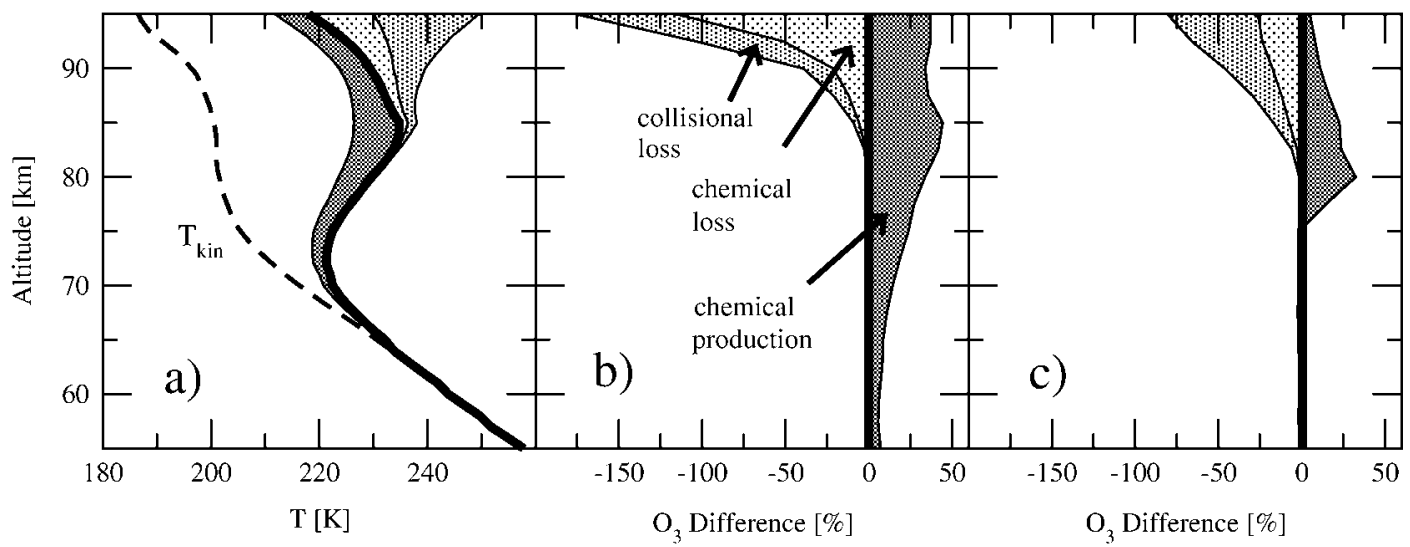

Figure 5. Dependence of (a) the daytime $\mathrm{O}_{3}(001)$ vibrational temperature, (b) the retrieved daytime and (c) nighttime ozone density on the recombination reaction ("chemical source"), the reactant loss via $\mathrm{O}+$ $\mathrm{O}_{3}$ ("chemical loss") and the chemical loss in combination with the collisional relaxation via atomic oxygen ("collisional loss").

affected by $20 \%$; details are given by F. J. Martín-Torres et al. (manuscript in preparation, 2002).

[21] A second distinctive feature of non-LTE models is how the chemical excitation relaxes through the different vibrational modes and in which way atomic oxygen is involved [Rawlins et al., 1987; Mlynczak and Drayson, 1990a; Manuilova and Shved, 1992; Manuilova et al., 1998]. The deactivation of $\mathrm{O}_{3}^{*}$ by atomic oxygen takes place through vibrational relaxation or by chemical reaction, but the branching ratio between reaction and quenching is not well known [Steinfeld et al., 1987]. The rate constants used in our model are those used in model 1 of Manuilova et al. [1998].

[22] The vibrational excitation $n_{i}$ of a vibrational state $i$ can be calculated from a steady state balance between the production (numerator) and loss processes (denominator):

$$
\begin{gathered}
n_{i}=\frac{P_{i}[\mathrm{O}]\left[\mathrm{O}_{2}\right][\rho]+a\left[\mathrm{O}_{3}\right]}{b\left[\mathrm{O}_{3}\right]} \\
a=\sum_{j} J_{i j} n_{j}+\sum_{j} k_{i j}^{\mathrm{M}} n_{j}[\mathrm{M}]+\sum_{j} k_{i j}^{\mathrm{O}} n_{j}[\mathrm{O}] \\
b=L_{i}[\mathrm{O}]+\sum_{j} J_{j i}+\sum_{j} k_{j i}^{\mathrm{M}}[\mathrm{M}]+\sum_{j} k_{j i}^{\mathrm{O}}[\mathrm{O}]
\end{gathered}
$$

[23] $J_{i j}\left(J_{j i}\right)$ are the radiative production (loss) coefficients. They are almost independent of the ozone concentration, because the atmosphere is optically thin for this radiation. $k_{i j}^{\mathrm{O} / \mathrm{M}}\left(k_{j i}^{\mathrm{O} / \mathrm{M}}\right)$ are the rate coefficients for collisions with atomic oxygen $(\mathrm{O})$ and $\mathrm{N}_{2}+\mathrm{O}_{2}(\mathrm{M})$. [O 3 , [O], [O $\left.\mathrm{O}_{2}\right]$ and $[\mathrm{M}]$ are the number densities of ozone, atomic and molecular oxygen and $\mathrm{N}_{2}+\mathrm{O}_{2} \cdot \rho$ is the total density of the atmosphere. $P_{i}$ gives the fraction of $\mathrm{O}_{3}^{*}$ produced in vibrational state $i$ in the $\mathrm{O}+\mathrm{O}_{2}+\mathrm{M}$ recombination reaction and $L_{i}$ the chemical loss due to the reaction $\mathrm{O}_{3}^{*}+\mathrm{O}$. This equation set up for all vibrationally excited levels forms the statistical equilibrium equations. Unknowns are the (relative) populations $n_{i}$, the ozone and the atomic oxygen densities. In the mesosphere, ozone and atomic oxygen are in photochemical equilibrium and the ratio is determined by the following chemical reactions [e.g., Allen et al., 1984]:

$$
\begin{array}{ccc}
\mathrm{O}+\mathrm{O}_{2}+\mathrm{M} \stackrel{k_{1}}{\longrightarrow} & \mathrm{O}_{3}+\mathrm{M} \\
\mathrm{O}+\mathrm{O}_{3} & \stackrel{k_{2}}{\longrightarrow} & 2 \mathrm{O}_{2} \\
\mathrm{H}+\mathrm{O}_{3} & \stackrel{k_{3}}{\longrightarrow} & \mathrm{OH}+\mathrm{O}_{2} \\
\mathrm{O}_{3}+h \nu & \stackrel{J_{4}}{\longrightarrow} & \mathrm{O}_{2}+\mathrm{O} \\
\mathrm{O}_{3}+h \nu & \stackrel{J_{5}}{\longrightarrow} & \mathrm{O}_{2}+\mathrm{O}\left({ }^{1} D\right)
\end{array}
$$

[24] $M$ is the total density. The densities of atomic oxygen and ozone are nearly proportional, which leads to the fact that $n_{i}$ is not explicitly dependent on the atomic oxygen density, if loss processes with atomic oxygen can be neglected [Mlynczak and Drayson, 1990a]. At altitudes where the reduction of vibrationally excited ozone by collisions or chemical reactions with atomic oxygen become important ( $>85 \mathrm{~km}$; compare Figure 5), the vibrational temperature of ozone is no longer independent of the atomic oxygen concentration. Above $90 \mathrm{~km}$, an enhancement of the atomic oxygen or ozone concentration leads to a decrease of the vibrational temperature and to an increase of the retrieved ozone density. The chemical deactivation of $\mathrm{O}_{3}^{*}$ changes the vibrational temperature of daytime $\mathrm{O}_{3}(001)$ by $1.5 \mathrm{~K}$ at 85 $\mathrm{km}, 5 \mathrm{~K}$ at $90 \mathrm{~km}$ and $12 \mathrm{~K}$ at $95 \mathrm{~km}$. The retrieved daytime (nighttime) ozone densities differ by $6 \%(8 \%)$ at $85 \mathrm{~km}, 20 \%$ $(18 \%)$ at $90 \mathrm{~km}$ and $115 \%(25 \%)$ at $95 \mathrm{~km}$. If the chemical loss is considered for the $\mathrm{O}_{3}, 010,001$ and 100 modes only [cf. Mlynczak and Drayson, 1990a], retrieved ozone differs by $4 \%(4 \%)$ at $85 \mathrm{~km}, 12 \%(12 \%)$ at $90 \mathrm{~km}$ and $90 \%(20 \%)$ at $95 \mathrm{~km}$. Chemical loss combined with quenching loss by atomic oxygen affects ozone by $9 \%(17 \%)$ at $85 \mathrm{~km}, 40 \%$ $(50 \%)$ at $90 \mathrm{~km}$ and $175 \%(80 \%)$ at $95 \mathrm{~km}$. These numbers give the main difference to ozone that is retrieved by means of non-LTE models that neglect loss mechanisms with atomic oxygen [e.g., Mlynczak and Zhou, 1998].

[25] For the error estimation of the CRISTA ozone we apply the uncertainties in the collisional and chemical rates 
Table 1. Systematic Errors of Retrieved Ozone Densities As a Percentage $^{\mathrm{a}}$

\begin{tabular}{|c|c|c|c|c|c|c|c|}
\hline \multirow[b]{2}{*}{$\begin{array}{c}z, \\
\mathrm{~km}\end{array}$} & \multirow[b]{2}{*}{$\mathrm{CO}_{2}$} & \multirow[b]{2}{*}{$\mathrm{T}_{\mathrm{KIN}}{ }^{\mathrm{b}}$} & \multirow[b]{2}{*}{$\mathrm{O}\left({ }^{3} \mathrm{P}\right)$} & \multirow[b]{2}{*}{ Instrument } & \multicolumn{2}{|c|}{ Non-LTE Model } & \multirow[b]{2}{*}{ RSS } \\
\hline & & & & & $\begin{array}{c}\text { Without } \\
\mathrm{O}\left({ }^{3} \mathrm{P}\right)\end{array}$ & $\begin{array}{l}\mathrm{O}\left({ }^{3} \mathrm{P}\right) \\
\text { Only }^{\mathrm{c}}\end{array}$ & \\
\hline 50 & & 15 & & 15 & 13 & & 25 \\
\hline 60 & & 10 & & 14 & 13 & & 22 \\
\hline 70 & $2^{\mathrm{d}}$ & 5 & & 13 & 7 & & 16 \\
\hline 85 & $1.5^{\mathrm{d}}$ & 3 & $5,^{e} 5^{d}$ & 18 & 31 & 15 & 39 \\
\hline 90 & $2^{\mathrm{d}}$ & 4 & $15,{ }^{\mathrm{e}} 4^{\mathrm{d}}$ & 18 & 25 & 15 & 36 \\
\hline 95 & $2^{\mathrm{d}}$ & 4 & $25,{ }^{\mathrm{e}} 4^{\mathrm{d}}$ & 24 & 21 & 12 & $35,{ }^{\mathrm{d}} 42^{\mathrm{e}}$ \\
\hline
\end{tabular}

${ }^{\mathrm{a}}$ Two values are given, if the errors for daytime and nighttime profiles differ significantly. The non-LTE model error "without $\mathrm{O}\left({ }^{3} \mathrm{P}\right)$ " contains uncertainties in the model parameters except for collisional and chemical loss processes with $\mathrm{O}\left({ }^{3} \mathrm{P}\right)$, which are listed separately (" $\mathrm{O}\left({ }^{3} \mathrm{P}\right)$ only"). RSS gives the root sum square of all columns.

${ }^{\mathrm{b}}$ Not for polar summer latitudes.

${ }^{\mathrm{c}}$ Significantly higher if loss processes with $\mathrm{O}\left({ }^{3} \mathrm{P}\right)$ are neglected (for details see text).

${ }^{\mathrm{d}}$ Daytime profiles.

eNighttime profiles.

published by West et al. [1978], which result in $12-15 \%$ uncertainty of ozone in the UMLT (Table 1, "Non-LTE Model $\mathrm{O}\left({ }^{3} \mathrm{P}\right)$ only"). Uncertainties in the collisional rates with $\mathrm{N}_{2}$ and $\mathrm{O}_{2}$ for the fundamental levels [Menard et al., 1992; Doyennette et al., 1992] result in a systematic error of $15 \%$ or less.

[26] In the lower mesosphere, the dominant retrieval error is given by uncertainties in the Einstein coefficients. They are $5 \%$ for the $\nu_{3}$ fundamental band and up to $200 \%$ for hot bands (J. M. Flaud, private communication, 1998). Below $70 \mathrm{~km}$ this is the main source of error and retrieved ozone densities are affected by 7-13\% (Table 1, "Non-LTE Model without $\mathrm{O}\left({ }^{3} \mathrm{P}\right)$ ") $)$.

\subsection{Atomic Oxygen}

[27] Due to the positive feedback of atomic oxygen on retrieved ozone above $90 \mathrm{~km}$, the inversion of the infrared radiances to ozone number densities is no longer well-posed without an additional constraint. This constraint is introduced as a fixed value of odd oxygen molecules at a specific altitude. Above $90 \mathrm{~km}$ more than $99 \%$ of odd oxygen is atomic oxygen and therefore this is equivalent to a predescribed atomic oxygen profile. In the retrieval atomic oxygen is taken from the GRAM model for daytime above $90 \mathrm{~km}$ and for nighttime at all altitudes. The influence of this constraint on the retrieved ozone is examined quantitatively for daytime and nighttime conditions by the sensitivity $k$ (Figure 6):

$$
k=\frac{\Delta O_{3} / O_{3}}{\Delta O\left({ }^{3} P\right) / O\left({ }^{3} P\right)}
$$

which describes the propagation of uncertainties in $\mathrm{O}\left({ }^{3} \mathrm{P}\right)$ into retrieved ozone. Photochemical equilibrium was not adjusted for the daytime profiles to evaluate the altitude of the zero-crossing of $k$. If photochemical equilibrium is adjusted below $90 \mathrm{~km}$, all daytime values are zero below this altitude. Whether the amount of atomic oxygen was increased or decreased at all altitudes simultaneously or at certain altitudes, only, has scarcely any effect on $k$, e.g., the dependence of ozone on the amount of atomic oxygen is mostly local. Besides, the sensitivity $k$ is nearly invariant to the magnitude of the variations of the initial atomic oxygen profile, so at a certain altitude retrieved ozone is approximately proportional to the amount of atomic oxygen. For daytime $k$ decreases from -0.1 at $60 \mathrm{~km}$ to -0.7 at $85 \mathrm{~km}$, then it increases rapidly to 0 around $90 \mathrm{~km}$ and up to 0.3 at $95 \mathrm{~km}$. Qualitatively the altitude course of the nighttime profile is very similar. The negative feedback below $85 \mathrm{~km}$ is weaker than for daytime, because the $O\left({ }^{3} \mathrm{P}\right) / \mathrm{O}_{3}$ ratio is much smaller or zero in the night.

[28] The uncertainty of atomic oxygen is determined by the quantities needed for the calculation of the photochemical equilibrium with ozone. The rate constants are taken from DeMore et al. [1997] and the photolytic rate constants are calculated by means of a photochemical model [Lary, 1991]. The atomic hydrogen profile is taken from MSIS-90 [Hedin, 1991]. If a 15\% uncertainty in the Hartley band photolysis rate is assumed, it results in $2-4 \%$ uncertainty in the retrieved ozone [Mlynczak and Zhou, 1998]. A 50\%uncertainty in atomic hydrogen [cf. Thomas, 1990] affects retrieved ozone at maximum $6 \%$ at $82 \mathrm{~km}$. The sum of both is given in Table 1 .

[29] For nighttime conditions an accuracy and precision of $50 \%$ of the atomic oxygen model profiles is assumed [cf. Thomas, 1990]. This affects retrieved nighttime ozone densities by $15 \%$ around $80 \mathrm{~km}, 5 \%$ at $85 \mathrm{~km}, 15 \%$ at 90 $\mathrm{km}$ and $25 \%$ at $95 \mathrm{~km}$.

\subsection{Kinetic Temperature}

[30] Kinetic temperature is another important factor in the retrieval of ozone from $9.6 \mu \mathrm{m}$ radiance. The dependence on the kinetic temperature is extremely nonlocal in the upper mesosphere, because the vibrational excitation of ozone is mainly determined by upwelling radiation. To investigate

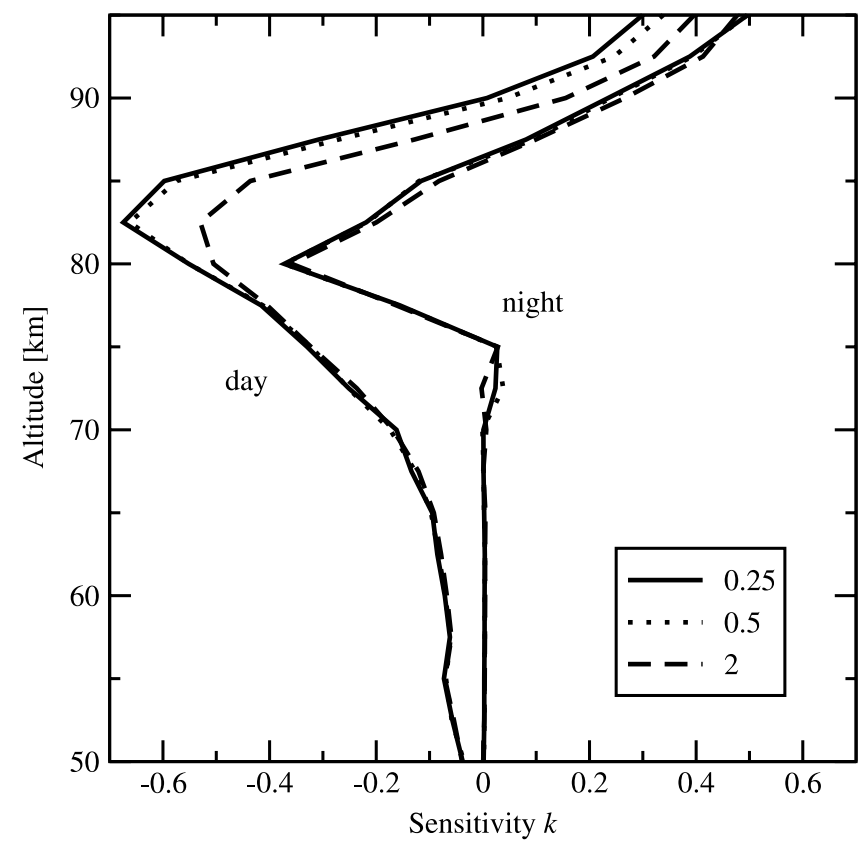

Figure 6. Sensitivity $k$ of retrieved ozone to variations of the atomic oxygen density profile; the magnitude (multiplicative factor) is displayed in the legend. The atmospheric condition is the same as for Figure 5. 


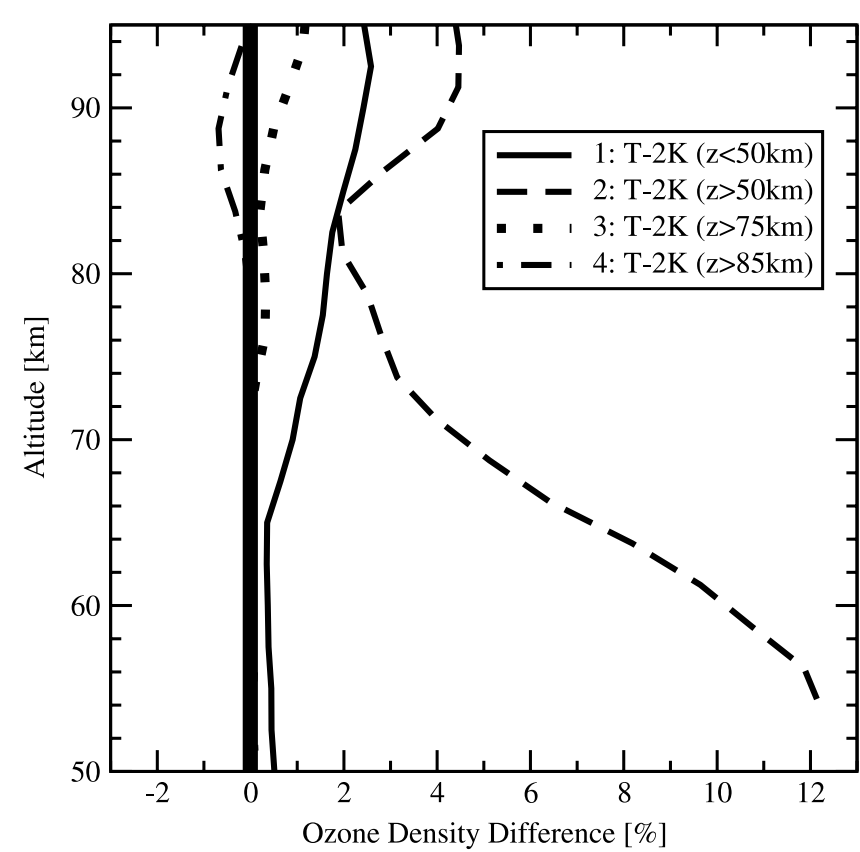

Figure 7. Sensitivity of the retrieved ozone density to different temperature shifts. 1: T-2 K for altitudes $z<50 \mathrm{~km}$; 2: T-2 K for $z>50 \mathrm{~km}$; 3: T-2 K for $z>75 \mathrm{~km}$; 4 : T-2 K for $z>85 \mathrm{~km}$.

this dependence, temperature shifts above or below a certain altitude were applied to the nominal profile. The magnitude of the shifts is $2 \mathrm{~K}$, which is the typical uncertainty of the CRISTA temperatures [Riese et al., 1999]. Hydrostatic equilibrium is adjusted in all cases.

[31] A temperature decrease of $2 \mathrm{~K}$ applied at all altitudes below $50 \mathrm{~km}$, which is the lower boundary of the meso- spheric ozone retrieval, is taken to estimate the uncertainty of ozone due to the error of the stratospheric temperatures. This temperature shift (Figure 7) has no effect on the ozone retrieval in the lower mesosphere, because the vibrational states of ozone are mostly in LTE at these altitudes and therefore they are not affected by changes in the upwelling radiation. In the UMLT the upwelling radiation becomes important for the excitation of vibrational modes and therefore daytime ozone increases by $2-3 \%$ and nighttime profiles by up to $4 \%$ due to the decrease in the stratospheric temperatures.

[32] Uncertainties of the temperature profile in the lower mesosphere, where the ozone retrieval compensates the decrease of temperature by an increase of ozone density, are much more important. A temperature decrease of $2 \mathrm{~K}$ applied at all altitudes above $50 \mathrm{~km}$ raises the ozone density by $10-15 \%$ between 50 and $60 \mathrm{~km}$. The increase of ozone density in this altitude regime increases the optical thickness of the atmosphere for upwelling radiation and the upwelling radiation is depleted. Therefore UMLT ozone must be increased up to $5 \%$ to balance this effect.

[33] If the same temperature shift is applied at altitudes above $75 \mathrm{~km}$, only, there is scarcely any effect on the ozone density retrieval. One reason is that the ozone density is too low to filter significant parts of the upwelling radiation and the second is that the temperature dependence of the quenching rates is relatively low.

[34] For the ozone density retrieval the operational CRISTA temperatures, which were retrieved without accounting for non-LTE effects, are used up to $90 \mathrm{~km}$. Between 75 and $90 \mathrm{~km}$ CRISTA temperatures are merged smoothly into GRAM temperatures and above $90 \mathrm{~km}$ only GRAM temperatures are used. Figure 8 shows the difference between these temperatures and the preliminary CRISTA-2 temperatures, which were derived using a nonLTE model [Grossmann et al., 2002]. For nonpolar latitudes

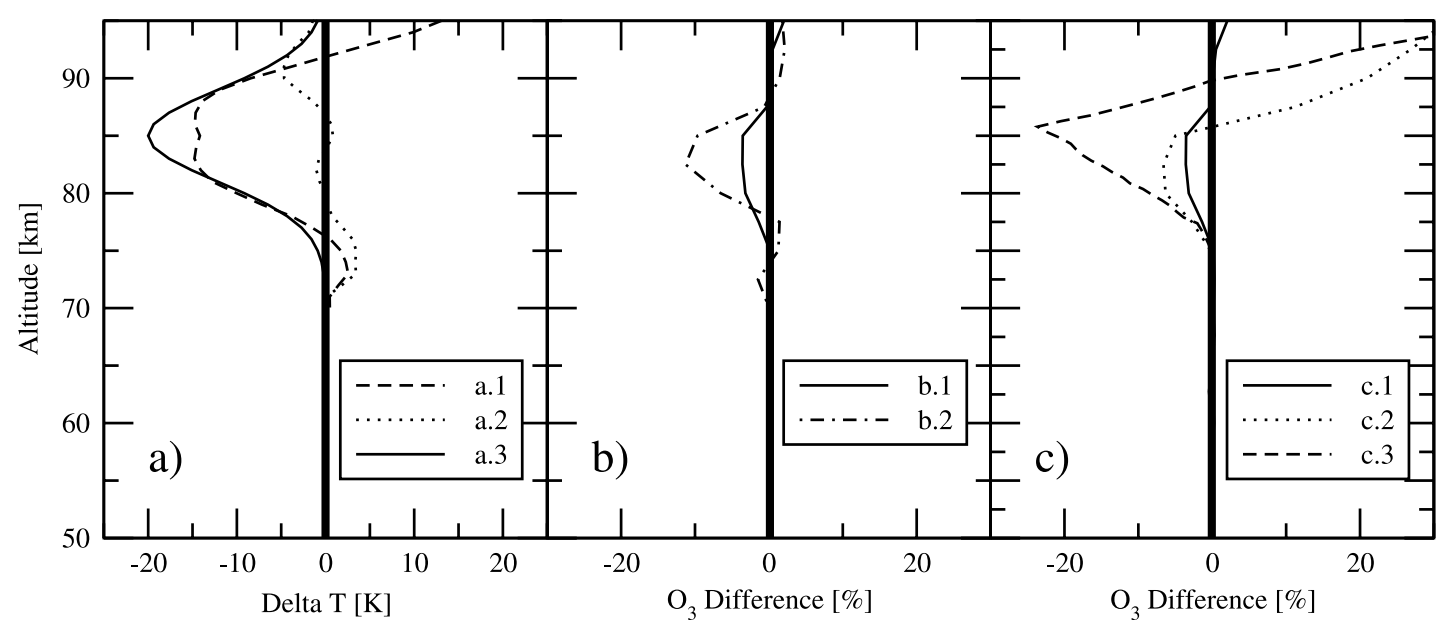

Figure 8. Sensitivity of the ozone retrieval on the very low temperatures at the polar summer mesopause. (a) Difference between the upper mesospheric temperature profiles from the GRAM model and the preliminary CRISTA-2 temperatures for polar summer latitudes $\left(>65^{\circ} \mathrm{N}\right.$, curve a.1) and other latitudes (curve a.2). Curve a.3 is a fit to curve a.1 (for details see text). (b) Ozone density difference for daytime (b.1) and nighttime (b.2) conditions on the temperature shift shown in curve a.3. (c) Dependence of the daytime ozone difference on the choice of the vertical coordinate. Curve c.1: ozone densities compared on geometric altitudes $z$ (c.f curve b.1); curve c.2: ozone VMRs compared on $z$; curve c.3: ozone VMRs compared on pressure levels. 
the globally averaged difference is within $\pm 5 \mathrm{~K}$, but for high northern (polar summer) latitudes the non-LTE temperatures are $15 \mathrm{~K}$ colder at the mesopause. Since the CRISTA nonLTE temperatures at the polar summer mesopause agree very well with temperatures obtained by in-situ techniques [Grossmann et al., 2002], this difference is taken to estimate the error of the polar summer mesopause ozone densities. The increase of the CRISTA non-LTE temperatures above $90 \mathrm{~km}$ depends strongly on the atomic oxygen profile used in the retrieval. To study the effect of the cold mesopause on the $\mathrm{O}_{3}$ retrieval, only, the temperature depletion at $85 \mathrm{~km}$ is fitted by a Gaussian (compare Figure 8a, profile a.3) and is used for the further analysis.

[35] If ozone density vs. geometric altitude is considered, this temperature shift affects the retrieved ozone densities by less than 5\% (compare Figure 8b). If ozone VMR vs. geometric height is analyzed, the change of the hydrostatic pressure $p_{h}(13 \%$ at $85 \mathrm{~km}, 22 \%$ at $90 \mathrm{~km})$ and the temperature dependence of the total density $\rho$ according to the ideal gas law is important. The explicit temperature dependence of $\rho$ is opposite to the temperature dependence of $p_{h}$. As a result, $\rho$ decreases up to $4 \%$ at $75-85 \mathrm{~km}$ and increases above $(17 \%$ at $90 \mathrm{~km})$. In consequence, the ozone VMR difference vs. geometric height is similar to the $\mathrm{O}_{3}$ density difference in the mesosphere but rises rapidly up to $-35 \%$ in the lower thermosphere (compare Figure $8 \mathrm{c}$ ).

[36] If ozone VMRs are compared on pressure levels, differences become much larger due to the extreme altitude gradient of the ozone VMR profile (e.g., $+10 \% / \mathrm{km}<70$ $\mathrm{km},-30 \% / \mathrm{km}$ at $85 \mathrm{~km}$ ). At $5 \cdot 10^{-3}$ mbar (approx. $85 \mathrm{~km}$ ) the corresponding geometric altitudes differ by $0.35 \mathrm{~km}$, which corresponds to a $10 \%$ change in the ozone VMR. Therefore, the ozone VMR difference vs. pressure height is up to $20 \%$ in the upper mesosphere.

\subsection{Instrumental Effects}

[37] The accuracy of the derived ozone profiles reported here critically depends on the accuracy of the calibration of the CRISTA 9.6 $\mu \mathrm{m}$ channels. Raw data corrections and the radiometric and wavelength calibrations are described in detail by Riese et al. [1999]. The most significant error in the radiometric calibration of the mesospheric channels is stray-light in the baffle system of the telescope during the calibration and in-flight stray-light in the spectrometer. The uncertainty of the $9.6 \mu \mathrm{m}$ radiance due to these effects is typically $2 \%$ below $70 \mathrm{~km}, 6 \%(10 \%)$ at $85 \mathrm{~km}$ and $16 \%$ $(11 \%)$ at $95 \mathrm{~km}$ for daytime (nighttime) profiles. The nonlinear relaxation character of the detectors enhances the uncertainty by $4 \%$ [Ern, 2000]. Another disturbing effect which must be taken into account is the accuracy with which the line of sight of the spectrometers can be determined. The accuracy of the tangent height determination is $300 \mathrm{~m}$, which affects retrieved ozone density (versus height) typically by $10 \%$. In total, the systematic error of retrieved ozone due to instrumental effects is typically $15 \%$ in the mesosphere and $25 \%$ in the lower thermosphere.

[38] The precision of CRISTA ozone is affected by detector noise, remaining effects of raw data corrections and the tangent height determination. The influence of these error sources was analysed by means of Monte Carlo simulations. The random error of retrieved daytime (nighttime) ozone due to instrumental effects is $2 \%(2 \%)$ at

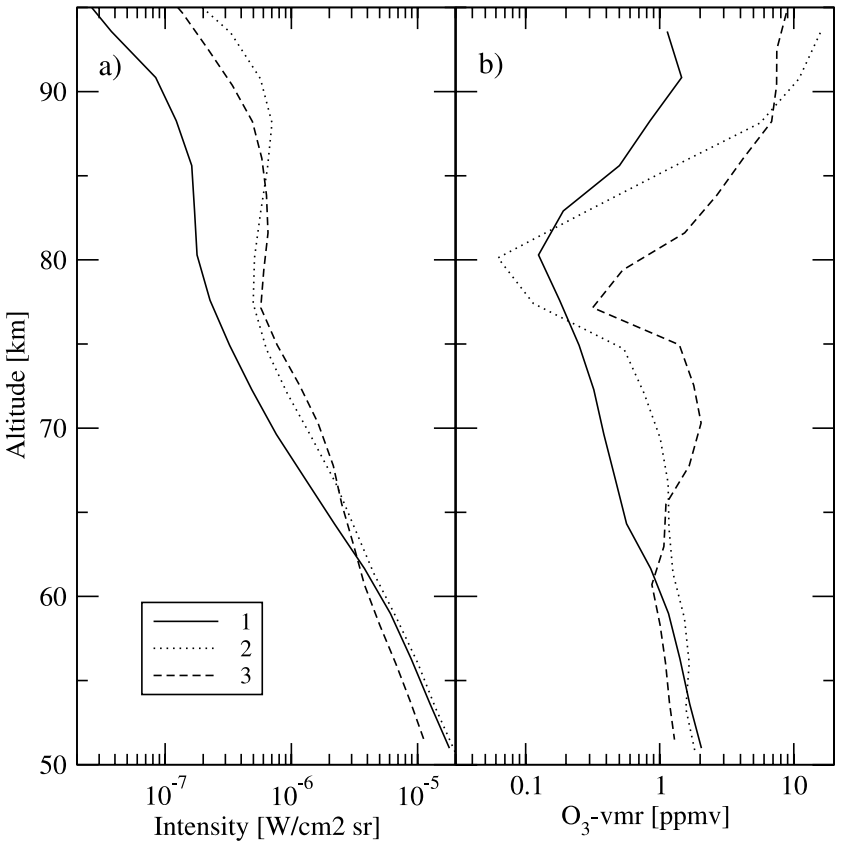

Figure 9. (a) CRISTA-1 and -2 wavenumber integrated radiance measurements $\left(1010-1065 \mathrm{~cm}^{-1}\right)$. (b) Retrieved ozone VMRs. Curve 1 shows CRISTA-1 daytime scan 201 at $39^{\circ} \mathrm{S}, 123^{\circ} \mathrm{E}$ on November 4,1994 ; curve 2 is CRISTA-1 nighttime scan 10412 at $51^{\circ}, 109^{\circ} \mathrm{W}$ on November 9,1994 and curve 3 was measured during nighttime at $70^{\circ} \mathrm{S}, 73^{\circ} \mathrm{W}$ on August 15, 1997 during CRISTA-2 (scan 12788).

$60 \mathrm{~km}, 6 \%(3 \%)$ at $70 \mathrm{~km}, 30-50 \%(10-20 \%)$ at the ozone minimum around $78 \mathrm{~km}, 20-30 \%(6-7 \%)$ at $85 \mathrm{~km}$, and $100 \%(15 \%)$ at $95 \mathrm{~km}$.

\subsection{Summary of Errors}

[39] Table 1 summarizes the systematic errors of retrieved ozone depending on the a priori information of the atmospheric state, uncertainties in the non-LTE model parameters and instrumental effects. In the lower mesosphere uncertainties in the kinetic temperature, the non-LTE model and measurement uncertainties are similar, resulting in a systematic error of $20-30 \%$ in retrieved ozone. In the upper mesosphere uncertainties in the non-LTE model parameters are most significant, followed by instrumental effects. The typical systematic error is $30-40 \%$ in this altitude region. However, the good agreement between the CRISTA ozone data and ozone measurements by means of other techniques (see below) indicates that the uncertainty in the UMLT may be significantly lower (less than 25\%).

[40] The precision of retrieved ozone densities is dominated by the instrumental error sources. The random error of the kinetic Temperature $(1 \mathrm{~K})$ can be neglected. The precison of atomic oxygen is relevant for the retrieval of nighttime ozone, only. Above $85 \mathrm{~km}$ it affects ozone to the same degree as the instrumental error.

\section{Results}

[41] Figure 9a shows three wavenumber integrated radiance profiles from the two CRISTA missions. Curve 1 and 2 represent mid latitude daytime and nighttime profiles during 


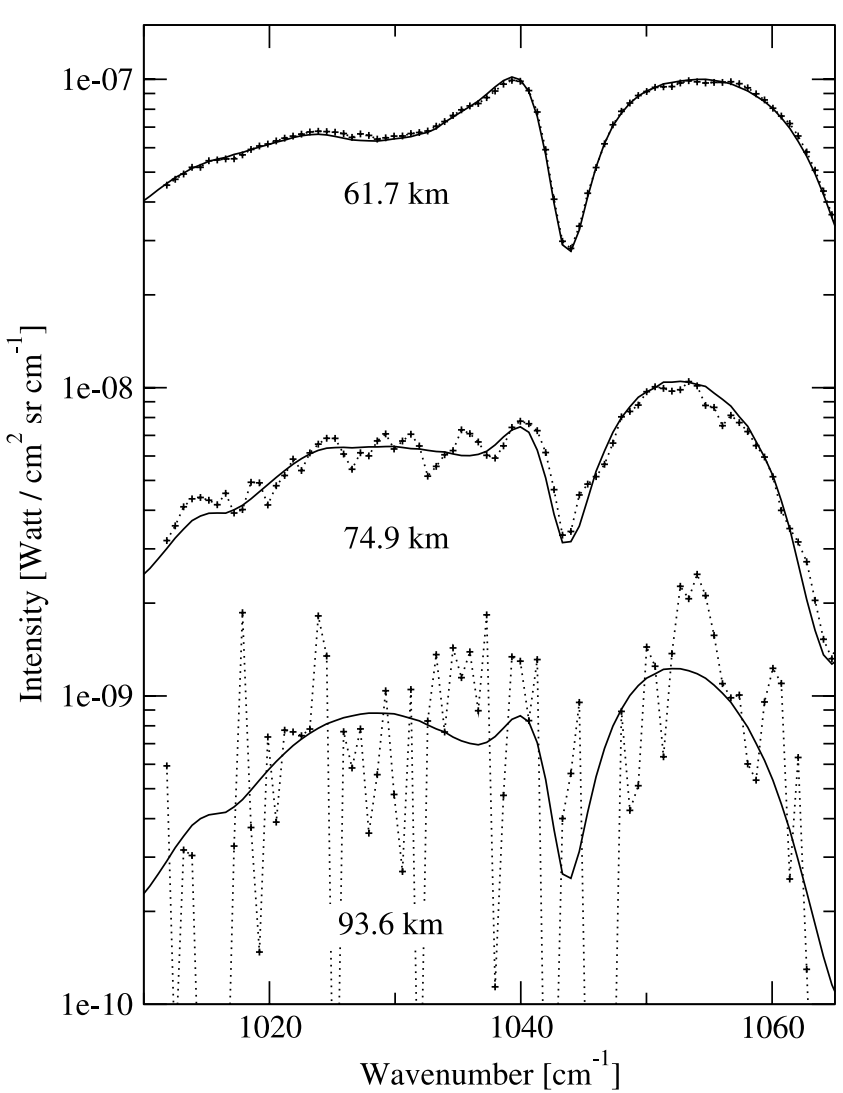

Figure 10. Comparison of measured (crosses) and simulated spectra (solid lines) for CRISTA-1 daytime scan 201 (compare Figure 9) for $61.7 \mathrm{~km}, 74.9 \mathrm{~km}$ and $93.6 \mathrm{~km}$ tangent altitude.

CRISTA-1 whereas scan 3 was measured at high southern latitudes during CRISTA-2. Model calculations using the ozone VMRs in Figure 9b fit these radiance profiles to $1.5 \%$ or better at all altitudes. Measured and simulated spectra (Figure 10) agree very well and there are no systematic discrepancies in the spectral fitting. At the stratopause the profiles show ozone VMRs of 1-2 ppmv. Higher up, the ozone VMR decreases with altitude, having a deep minimum of $0.1-0.5 \mathrm{ppmv}$ around $75-80 \mathrm{~km}$. At higher altitudes the mixing ratio is increasing again, reaching 1.5 ppmv for the daytime profile and 8-12 ppmv for the nightime profiles. The secondary maximum, which is supposed to be around $92 \mathrm{~km}$, is not clearly resolved in the CRISTA data, because the altitude of the maximum coincides with the upper boundary of the ozone retrieval. The local maximum around $72 \mathrm{~km}$ of curve 3 appears in all profiles at the polar night terminator and will be discussed later.

[42] Figure 11 shows a comparison between two daytime mean CRISTA-1 and CRISTA-2 ozone profiles for the same latitudes $\left(15-30^{\circ} \mathrm{N}\right)$ and similar local times. Both profiles agree within $10-20 \%$ at all altitudes and the difference between them is much smaller than their variability about the mean profile. A mean CRISTA-2 profile is also compared with ozone derived from the HRDI dayglow measurements [Marsh et al., 2002] and with MLS data [Livesey et al., 2003] (Figure 12). All profiles are for August, between $50^{\circ} \mathrm{N}$ and $60^{\circ} \mathrm{N}$, and mainly $14-16 \mathrm{~h}$ local time.
[43] The MLS data was cut above $85 \mathrm{~km}$ since the vertical resolution degrades from $6-7 \mathrm{~km}$ below $80 \mathrm{~km}$ to $12-15 \mathrm{~km}$ at higher altitudes (L. Froidevaux, personal communication, 2002). With the exception of the ozone minimum, the CRISTA, HRDI and MLS profiles differ by less than $30 \%$, which is usually less than their individual uncertainty. The variability of the CRISTA profiles is 20$30 \%$ in the upper mesosphere, $20-50 \%$ for the HRDI and $100-200 \%$ for the MLS data.

[44] Nighttime measurements of mesospheric ozone are very rare in comparison with the daytime measurements. Except for the microwave data no comprehensive global data set of nighttime ozone in the UMLT exists so far. Therefore it is not always possible to compare ozone profiles that match in all important conditions like season of the year, local time, and latitude. During the first hours of the night the ozone concentration varies significantly, because the conversion of odd oxygen to ozone just after sunset can take a few hours in the middle mesosphere [Prather, 1981]. Above $80 \mathrm{~km}$ the situation is different. The ozone concentration peaks just after sunset and decreases throughout the night due to loss reactions with odd hydrogen $\left(\mathrm{HO}_{x}\right)$. Just after sunset the ozone concentration can be increased by a factor of 10 (at $84 \mathrm{~km}$ ) in comparison with the midnight value [Prather, 1981].

[45] Figure 13a shows a comparison between CRISTA-1 and CRISTA-2 nighttime ozone VMRs for the same latitude $\left(40-55^{\circ} \mathrm{S}\right)$ and local time $(23-3 \mathrm{~h} \mathrm{LT})$. The two CRISTA profiles agree well below $75 \mathrm{~km}$, but above this altitude the CRISTA-2 profile is higher by up to a factor of 5 . At the altitude of the secondary ozone maximum both CRISTA profiles show similar values of 7-9 ppmv. However, the difference of the CRISTA- 1 and -2 profiles is smaller than

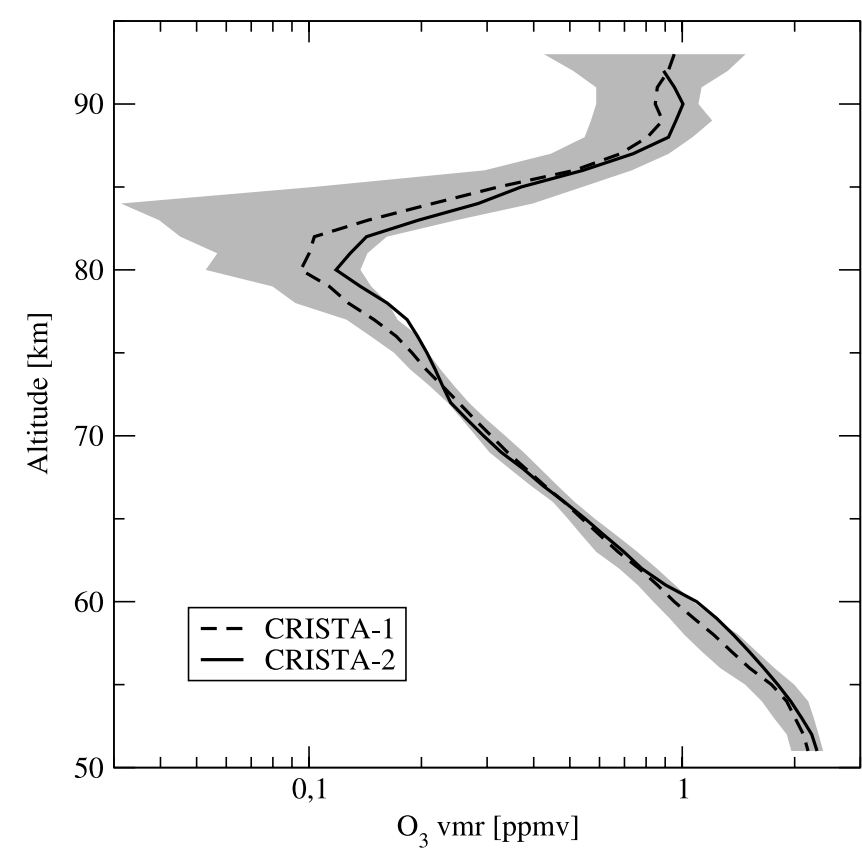

Figure 11. Volume mixing ratios of daytime ozone at 15$30^{\circ} \mathrm{N}$. The CRISTA-1 (CRISTA-2) profile is a mean of 39 (21) single profiles at $8.1-9.6 \mathrm{~h}$ LT $(7.5-8.5 \mathrm{~h} \mathrm{LT})$. The shaded area indicates the variability (standard deviation about the mean) of the CRISTA-1 profile. 


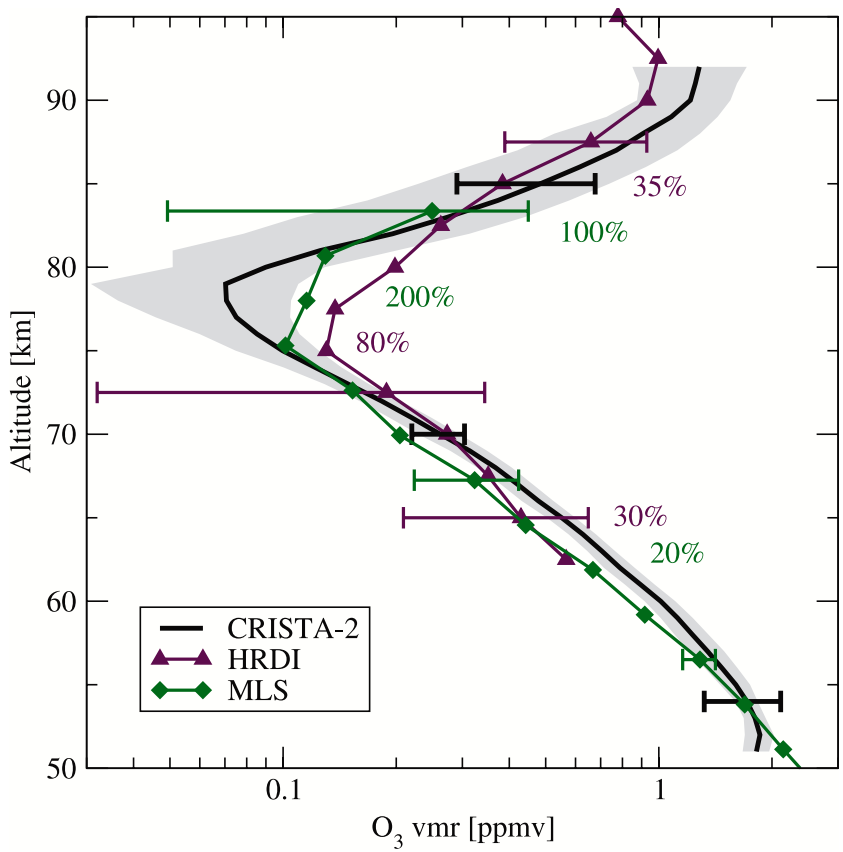

Figure 12. Volume mixing ratios of daytime ozone in comparison with other experiments. The CRISTA-2 curve is a mean of 35 profiles for $50-55^{\circ} \mathrm{N}, 15-18 \mathrm{~h}$ LT in August 1997. Error bars represent the systematic errors and the shaded area indicates the variability $\sigma$ (standard deviation about the mean). The HRDI data (mean of 55 single profiles) is for August 1997, 50-60 ${ }^{\circ} \mathrm{N}, 14: 30-15: 30 \mathrm{~h} \mathrm{LT}$. The MLS data $(183 \mathrm{GHz}$, version 5, mean of 128 single profiles) is for August $1992,50-55^{\circ} \mathrm{N}, 14-16$ h LT. Green and violet numbers indicate the variability $\sigma$ of the MLS and HRDI data at selected altitudes. the combined standard deviation. The MLS profile also shown in the figure was taken under similar conditions as the CRISTA-2 profile (August 1997, $40-55^{\circ} \mathrm{S}$ ), and agrees very well with the CRISTA profiles up to $75 \mathrm{~km}$. The ozone minimum between $75 \mathrm{~km}$ and $80 \mathrm{~km}$ is less sharp in the MLS data, which is a consequence of the coarse altitude resolution of the MLS data.

[46] A comparison of the CRISTA-1 profile with CIRRIS-1A [Zhou et al., 1998] and MAS [Bevilacqua et al., 1996] data is shown in Figure 13b. The CIRRIS-1A ozone densities were converted to VMRs using MSIS-90 total densities. The agreement between the different profiles, which are all taken $20-50$ days after equinox $\left(40-55^{\circ} \mathrm{S}\right.$; $22.8-3 \mathrm{hr} \mathrm{LT}$ ), is within $30 \%$ at most altitudes and as large as the seasonal variation of the HRDI and MLS data. Especially the ozone VMR at the secondary maximum is very similar ( 8 ppmv). The comparison between CRISTA-1 and CIRRIS-1A ozone around $25-35^{\circ} \mathrm{S}$ (Figure 13c) gives a similar agreement. The difference at the ozone minimum at $78 \mathrm{~km}$ is much smaller in this case. The agreement of the various data sets is usually better than the combined uncertainties.

[47] The latitudinal distribution of CRISTA ozone is shown in Figure 14. Since space and local time varies simultaneously along the CRISTA orbital track and cannot be fully resolved due to the short duration of the CRISTA missions, these latitudinal distributions are significantly biased by the diurnal variation of ozone. The CRISTA-1 daytime data exhibit minimum ozone values above $80 \mathrm{~km}$ at the equator and two maxima at $90 \mathrm{~km}$ and mid latitudes. The CRISTA-1 nighttime data shows much stronger latitudinal structures: The CRISTA-1 data above $70 \mathrm{~km}$ are generally smaller in the southern hemisphere. Between

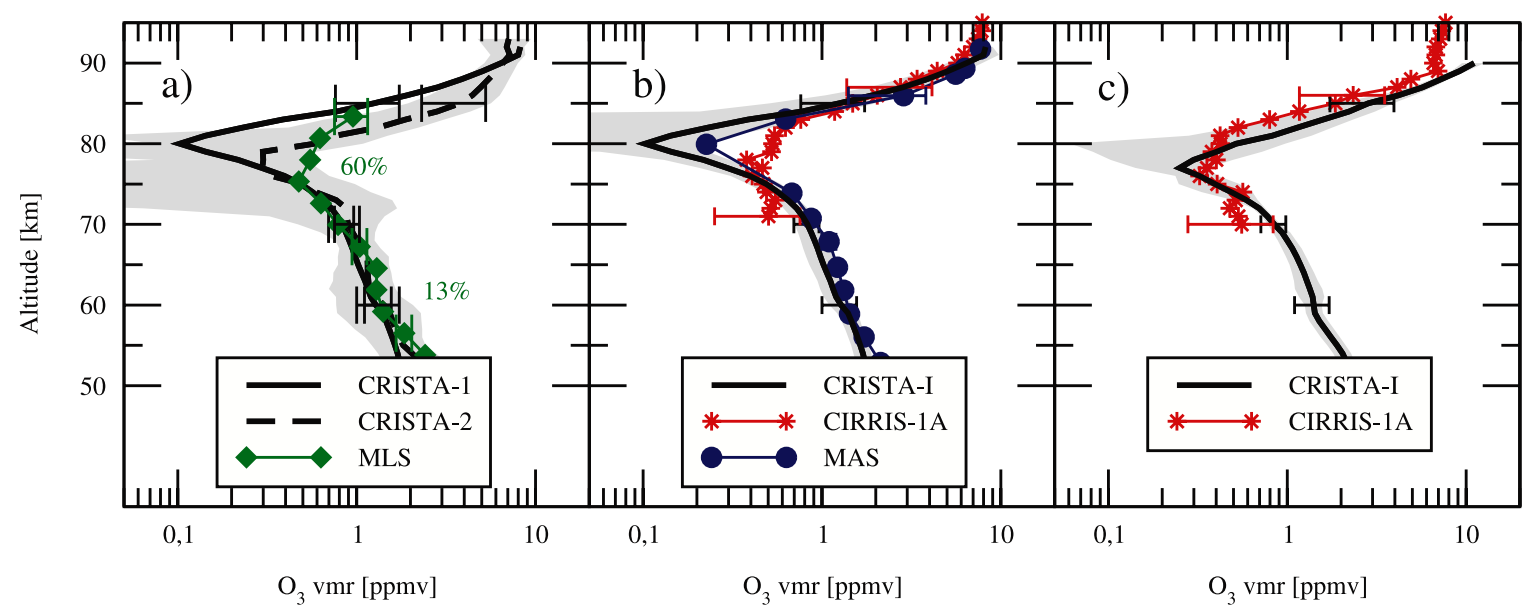

Figure 13. Volume mixing ratios of nighttime ozone in comparison with other experiments. (a) The CRISTA-1 curve (November 1994) is a mean of 120 single profiles; the CRISTA-2 profile (August 1997) is a mean of 17 single profiles and the shaded area indicates the variability $\sigma$ (standard deviation about the mean) of the CRISTA-2 profile. Error bars represent the systematic errors. The MLS curve (183 GHz, version 5) is for August 1992. The green numbers indicate the variability $\sigma$ of the MLS data at selected altitudes. All three profiles are for $40-55^{\circ} \mathrm{S}, 23-3 \mathrm{~h}$ LT. (b) The CRISTA-1 profile is from plot a); the shaded area indicates the standard deviation of this profile. The CIRRIS-1A curve is a mean profile for $44^{\circ} \mathrm{S}, 22: 49 \mathrm{~h} \mathrm{LT}$, measured in April/May 1991 and the MAS data is for $55^{\circ} \mathrm{S}, \mathrm{SZA}>110^{\circ}, 8-15$ April 1993. (c) The CRISTA-1 profile (mean of 11 single profiles) with its standard deviation is for $25-35^{\circ} \mathrm{N}$, $20-21 \mathrm{~h}$ LT. The CIRRIS-1A data is for $28^{\circ} \mathrm{S}, 1: 42 \mathrm{~h}$ LT in April/May 1991. 

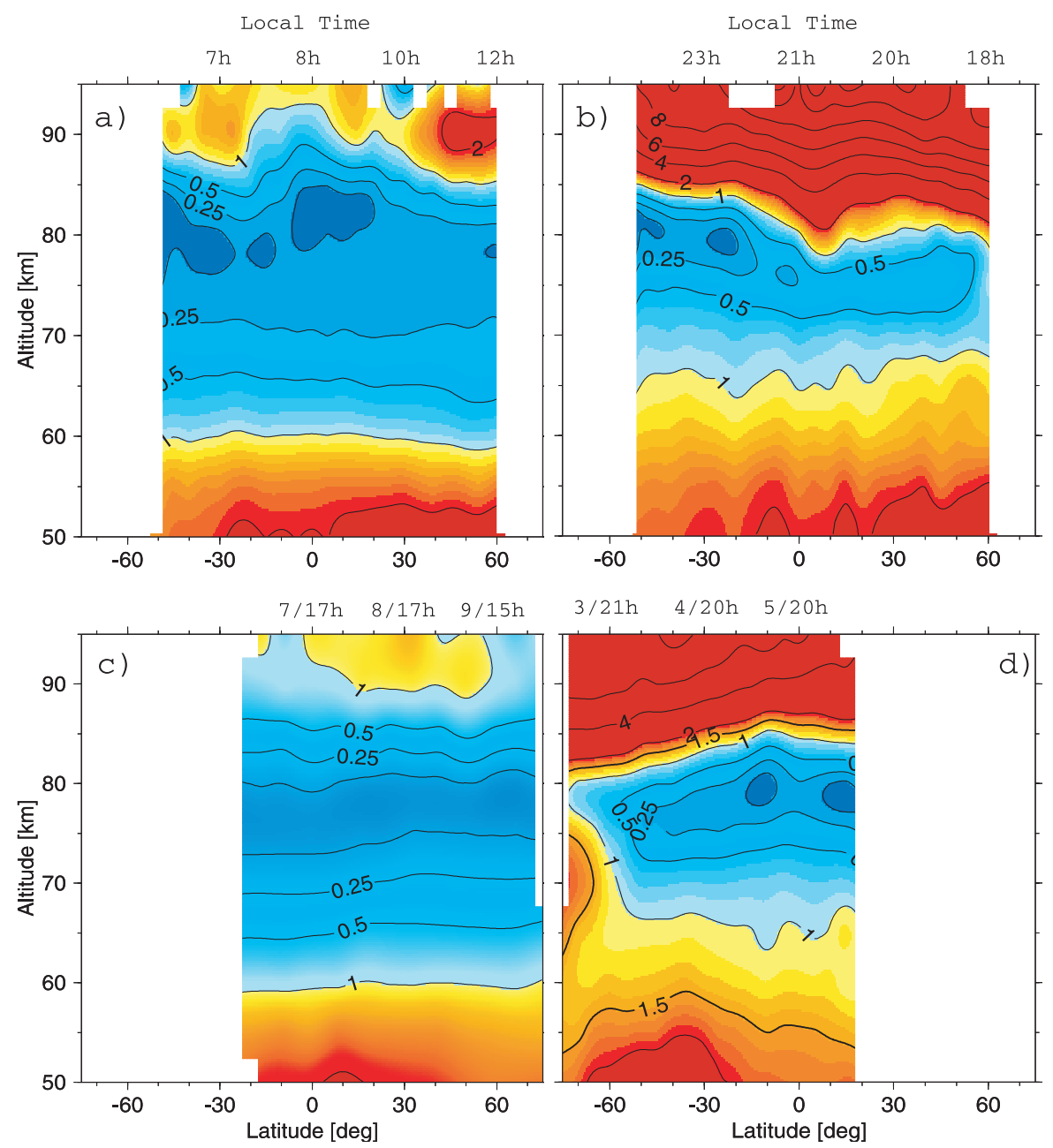

Figure 14. Latitudinal cross sections of ozone volume mixing ratio. Since space and local time varies simultaneously, approximative local times are given in the upper axes (for ascending and descending nodes of the orbit in case of CRISTA-2). The data was smoothed with a $5^{\circ} \cdot 5 \mathrm{~km}$ block-mean. The contour intervals are $0.125,0.25,0.5,1,2,4,6 \ldots$ ppmv. (a) CRISTA-1 daytime (b) CRISTA-1 nighttime (c) CRISTA-2 daytime (d) CRISTA-2 nighttime.

$50^{\circ} \mathrm{S}$ and $60^{\circ} \mathrm{N}$ the ozone VMR versus geometric altitude varies by a factor of $5-10$ at $80 \mathrm{~km}$, a factor of 6 at $85 \mathrm{~km}$ and a factor of 2 at $90 \mathrm{~km}$. The latitudinal gradient of ozone VMR versus pressure height (not shown) is a factor of two between $50^{\circ} \mathrm{S}$ and $60^{\circ} \mathrm{N}$ above $80 \mathrm{~km}$ and is constant with altitude. Additionally the CRISTA- 1 nighttime data show a mixing ratio maximum above $80 \mathrm{~km}$ at the equator. These features are also present in the MAS nighttime ozone data [Bevilacqua et al., 1996]. The CRISTA-2 nighttime data above $70 \mathrm{~km}$ shows much higher values at high southern latitudes: Between $70^{\circ} \mathrm{S}$ and $10^{\circ} \mathrm{N}$ the ozone VMR at polar latitudes is increased by a factor of $5-10(80 \mathrm{~km}), 3(85 \mathrm{~km})$ and $2(90 \mathrm{~km})$. At high polar winter latitudes $\left(>60^{\circ} \mathrm{S}\right)$ there is a distinctive ozone VMR maximum centered at $72 \mathrm{~km}$ in CRISTA-2 nighttime ozone (compare Figure 9, profile 3). The enhancement in the vertical is up to $50 \%$ and up to a factor of 3-4 in comparison with low latitudes. This enhancement is well above the variability and the systematic error of the profiles. This maximum was also observed by MLS in southern as well as northern polar winter latitudes (http://mls.jpl.nasa.gov/).
[48] The model analysis of Marsh et al. [2001] indicates that this maximum is the result of a decrease in atomic oxygen losses by catalytic cycles involving odd hydrogen, which is produced by water vapor photolysis. The optical thickness of the polar winter middle mesosphere is significantly higher for water vapor photolysis in comparison with molecular oxygen photolysis and yields an increase of atomic oxygen and ozone. The photochemical lifetime of odd-hydrogen and -oxygen $(2-3 \mathrm{~h}$ at $72 \mathrm{~km})$ is much less than the dynamical timescale (at $72 \mathrm{~km}$ several days for vertical and meridional transports) and transport effects are unimportant for the explanation of the third ozone maximum.

[49] The latitudinal distribution is compared with 3D model calculations performed by the ROSE model [Rose and Brasseur, 1989; Marsh et al., 2001]. The altitude range of the model is $17.5 \mathrm{~km}$ to $110 \mathrm{~km}$. ROSE incorporates chemistry for 27 species, including reactions important for odd-oxygen and odd-hydrogen. The photolysis rate coefficients were calculated with the TUV model [Madronich and Flocke, 1998]. The ROSE inputs for this study are consis- 

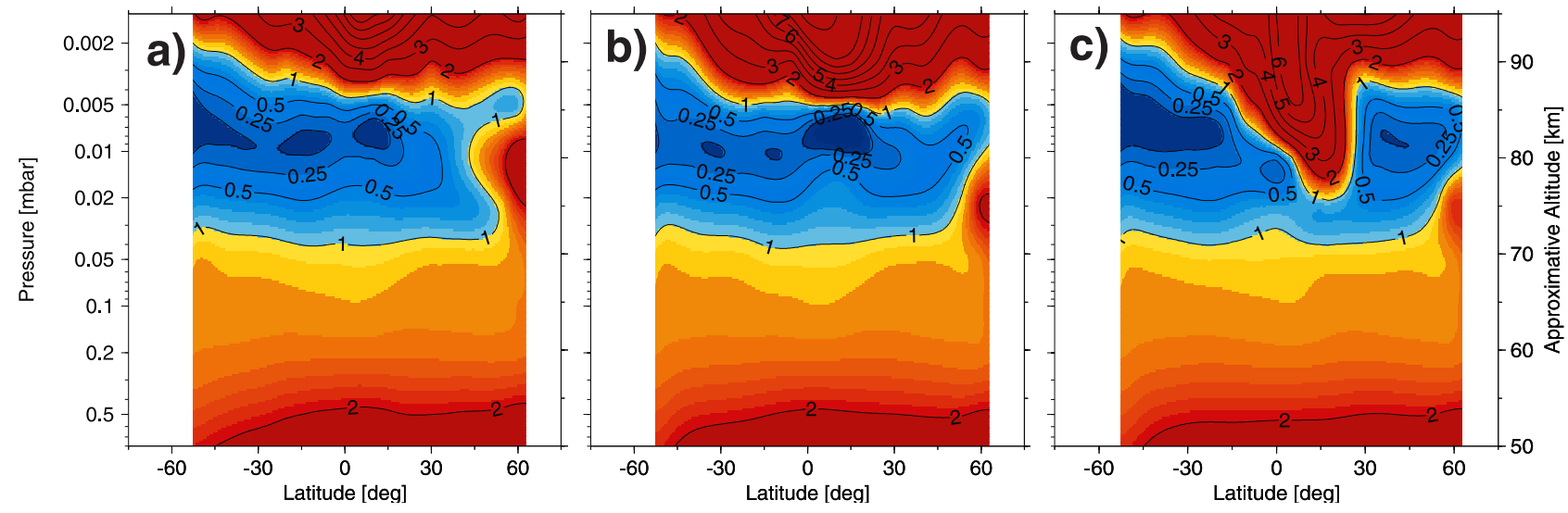

Figure 15. Latitudinal cross sections of ROSE ozone VMR for November 4, 1994. The contour intervals are $0.125,0.25,0.5,1,2,3,4,5 \ldots$ ppmv. (a) Sampled along the CRISTA- 1 orbital track using the local times of the CRISTA measurements. (b) $0^{\circ}$ longitude, $21 \mathrm{~h}$ LT. Latitudes are from the CRISTA-1 orbital track. (c) Compare Figure 15b, but for $3 \mathrm{~h} \mathrm{LT}$.

tent with the conditions that prevailed during November 1994: We used the NCAR global-scale wave model to specify migrating diurnal and semidiurnal tidal fields [e.g., Hagan et al., 1999] and NCAR National Center for Environmental Predictions (NCEP) reanalysis data (geopotential height, temperature, and horizontal winds) (http://dss.ucar. edu/pub/reanalysis/) accounted for the prevailing planetary wave activity at the $17.5 \mathrm{~km}$ lower boundary. The model data is sampled along the orbital track of the CRISTA-1 measurements in space and time (Figure 15a) and in space for fixed local times (Figures $15 \mathrm{~b}$ and 15c).

[50] Minimum ozone values are at similar altitudes and latitudes in the measured and modelled data and the absolute values are smaller than $0.25 \mathrm{ppmv}$ in both data sets. Ozone mixing ratios at the secondary maximum are higher in the CRISTA data (e.g., 12 ppmv at the equator) in comparison with the model ( 9 ppmv). The model data indicate the formation of a third ozone maximum at high northern latitudes for November 4, 1994, which is not present in the CRISTA-1 measurement. The latitudinal gradient in CRISTA-1 nighttime ozone is in general agreement with the model results: Mixing ratios at high southern latitudes are generally lower in both data sets.

[51] The ROSE model data indicate that the latitudinal gradients of ozone are significantly influenced by solar tides in the equatorial region. The downward transport of atomic oxygen due to the tides yields a strong enhancement of equatorial ozone in the upper mesosphere of up to a factor of ten and shows a strong nocturnal variation (compare Figures $15 \mathrm{~b}$ and 15c). The dynamical influences on the diurnal behavior of ozone at high northern latitudes are investigated by Bjarnason et al. [1987]. A detailed study of the impact of solar tides on the CRISTA ozone distribution will be presented elsewhere.

\section{Summary}

[52] Spectral limb radiance data for $\mathrm{O}_{3} 9.6 \mu \mathrm{m}$ emissions obtained in the CRISTA- 1 and -2 missions have been analyzed. A non-LTE model was used to perform the inversion of radiances to $\mathrm{O}_{3}$ number densities. In particular we report here the first massive single profile retrieval of a global data set of upper mesospheric ozone obtained by an infrared emission measurement. This paper describes the data set, retrieval method and an error analysis of the CRISTA ozone profiles.

[53] Altitude profiles of ozone show 1-2 ppmv at the stratopause, a distinct ozone minimum having less than 0.5 ppmv around $80 \mathrm{~km}$ and indicate ozone VMRs of typically 1 ppmv during daytime and 10 ppmv during nighttime at the secondary maximum.

[54] Upwelling radiation from the lower atmosphere is one of the most important excitation mechanisms of the emitting ozone molecules in the UMLT. Important sources of error in the lower mesosphere are uncertainties in the Einstein coefficients, in the kinetic temperature, and the instrumental errors; in the upper mesosphere uncertainties in the non-LTE model parameters and the instrument calibration dominate the total error of retrieved ozone.

[55] A comparison of day and nighttime ozone obtained by CRISTA and other measurements was made. The daytime data agree better than $25 \%$ with HRDI and MLS data. The nighttime data agrees very well with CIRRIS-1A and MAS nighttime ozone.

[56] The global distribution of CRISTA nighttime ozone shows distinctive latitudinal gradients and a characteristic maximum in the equatorial upper mesosphere. Calculations with the ROSE 3D atmospheric model indicate that this maximum is formed by downward transport of atomic oxygen due to atmospheric tides and that the latitudinal distribution is strongly biased by thermal tides. A third ozone maximum at $72 \mathrm{~km}$ is observed in CRISTA-2 nighttime ozone at high southern polar latitudes. Differences in the optical thickness of the atmosphere at these latitudes favor the photochemical production of odd oxygen in comparison with odd hydrogen and cause the formation of this maximum.

[57] Acknowledgments. The authors would like to thank R. O. Manuilova for fruitful discussions concerning the non-LTE modelling and L. Froidevaux for his assistance with the MLS data. We also thank A. K. Smith for her help with the ROSE model and David Lary for supplying his photochemical model. The work of M. Kaufmann is supported by BMBF through GSF, Forschungszentrum für Umwelt und Gesundheit $\mathrm{GmbH}$, grant 07ATF10. The CRISTA project was supported by grants $50 \mathrm{OE}$ 
8503, 50 OE 95012, 50 QV 9501 and 50 QV 9802 of BMBF through Deutsche Agentur für Weltraumangelegenheiten (DARA), Bonn, Germany. The National Center for Atmospheric Research is operated by the University Corporation for Atmospheric Research under the sponsorship of the National Science Foundation.

\section{References}

Adler-Golden, S. M., and D. R. Smith, Identification of 4- to 7-quantum $\nu_{3}$ bands in the atmospheric recombination spectrum of ozone, Planet Space Sci., 38, 1121-1132, 1990.

Adler-Golden, S. M., M. W. Matthew, D. R. Smith, and A. J. Ratkowski, The 9- to 12- $\mu \mathrm{m}$ atmospheric ozone emission observed in the SPIRIT 1 experiment, J. Geophys. Res., 95, 15,243-15,250, 1990.

Adler-Golden, S. M., J. Gruninger, and D. R. Smith, Derivation of atmospheric atomic oxygen and hydrogen profiles from ozone $v_{3}$ band emission, J. Geophys. Res., 97, 19,509-19,518, 1992.

Allen, M., J. I. Lunine, and Y. L. Yung, The vertical distribution of ozone in the mesosphere and lower thermosphere, J. Geophys. Res., 89, 48414872, 1984

Bevilacqua, R. M., et al., MAS measurements of the latitudinal distribution of water vapor and ozone in the mesosphere and lower thermosphere, Geophys. Res. Lett., 23, 2317-2320, 1996.

Bjarnason, G. G., S. Solomon, and R. R. Garća, Tidal influences on vertical diffusion and diurnal variability of ozone in the mesosphere, J. Geophys. Res., 92, 5609-5620, 1987.

Brasseur, G., and S. Solomon, Aeronomy of the Middle Atmosphere: Chemistry and Physics in the Stratosphere and Mesosphere, D. Reidel, Norwell, Mass., 1986.

Brühl, C., et al., Halogen occultation experiment ozone channel validation, J. Geophys. Res., 101, 10,217-10,240, 1996.

Cevolani, G., A. Hajduk, M. Hajdukova, V. Porubcan, and G. Trivellone, Ozone concentration at meteor heights determined from forward-scatter radar echoes, J. Atmos. Terr. Phys., 61, 539-543, 1999.

Chapman, S., On ozone and atomic oxygen in the upper atmosphere, Philos. Mag., 7, 369-383, 1930.

Connor, B. J., D. E. Siskind, J. J. Tsou, A. Parrish, and E. E. Remsberg, Ground-based microwave observations of ozone in the upper stratosphere and mesosphere, J. Geophys. Res., 99, 16,757-16,770, 1994.

DeMore, W. B., S. P. Sander, D. M. Golden, R. F. Hampson, M. J. Kurylo, C. J. Howard, A. R. Ravishankara, C. E. Kolb, and M. J. Molina, Chemical kinetics and photochemical data for use in stratospheric modeling, JPL Publ., 97-4, 1997.

Doyennette, L., C. Boursier, J. Menard, and F. Menard-Bourcin, $\mathrm{v}_{1}$ to or from $\mathrm{v}_{3}$, Coriolis assisted intermode transfers in $\mathrm{O}_{3}-\mathrm{M}$ gas mixtures $(\mathrm{M}=$ $\mathrm{O}_{2}$ and $\mathrm{N}_{2}$ ) in the temperature range $200-300 \mathrm{~K}$ from IR double-resonance measurements, J. Chem. Phys., 197, 157-160, 1992.

Edwards, D. P., M. López-Puertas, and M. G. Mlynczak, Non-local thermodynamic equilibrium limb radiance from $\mathrm{O}_{3}$ and $\mathrm{CO}_{2}$ in the $9-11 \mu \mathrm{m}$ spectral region, J. Quant. Spectrosc. Radiat. Transfer, 52, 389-407, 1994.

Ern, M., Relaxation effects of the CRISTA infrared detectors and their correction, Ph.D. thesis, Univ. of Wuppertal, Wuppertal, Germany, 2000

Evans, W. F. J., and E. J. Llewellyn, Measurements of mesospheric ozone from observations of the $1.27 \mu \mathrm{m}$ band, Radio Sci., 7, 44-50, 1972.

Evans, W. F. J., E. C. McDade, J. Yuen, and E. J. Llewellyn, A rocket measurement of the $\mathrm{O}_{2}$ infrared atmospheric (0-0) band emission in the dayglow and a determination of the mesospheric ozone and atomic oxygen densities, Can. J. Phys., 66, 941-946, 1988.

Fichet, P., J. R. Jevais, C. Camy-Peyret, and J. M. Fraud, NLTE processes in ozone: Importance of $\mathrm{O}$ and $\mathrm{O}_{3}$ densities near the mesopause, Planet. Space Sci., 40, 989-1009, 1992.

Froidevaux, L., et al., Validation of UARS Microwave Limb Sounder ozone measurements, J. Geophys. Res., 101, 10,017-10,060, 1996.

Fussen, D., F. Vanhellemont, and C. Bingen, Ozone profiles from 30 to 110 $\mathrm{km}$ measured by the Occultation Radiometer instrument during the period Aug 1992-Apr 1993, Geophys. Res. Lett., 27, 3449-3452, 2000.

Green, B. D., W. T. Rawlins, and R. M. Nadile, Diurnal variability of vibrationally excited mesospheric ozone as observed during the SPIRE mission, J. Geophys. Res., 91, 311-320, 1986.

Grossmann, K. U., and K. Vollmann, Thermal infrared measurements in the middle and upper atmosphere, Adv. Space Res., 19, 631-638, 1997.

Grossmann, K. U., D. Offermann, O. Gusev, J. Oberheide, M. Riese, and R. Spang, The CRISTA-2 mission, J. Geophys. Res., 107(D23), 8173, doi:10.1029/2001JD000667, 2002.

Gunson, M. R., C. B. Farmer, R. H. Norton, R. Zander, C. P. Rinsland, J. H Shaw, and B.-C. Gao, Measurements of $\mathrm{CH}_{4}, \mathrm{~N}_{2} \mathrm{O}, \mathrm{CO}, \mathrm{H}_{2} \mathrm{O}$, and $\mathrm{O}_{3}$ in the middle atmosphere by the Atmospheric Trace Molecule Spectroscopy experiment on Spacelab 3, J. Geophys. Res., 95, 13,876-13,882, 1990.
Hagan, M. E., R. G. Roble, C. Hartsough, J. Oberheide, and M. Jarisch, GSWM-98: Results for migrating solar tides, J. Geophys. Res., 104, $6813-6827,1999$

Hays, P. B., and R. G. Roble, Observation of mesospheric ozone at low latitudes, Planet. Space Sci., 21, 273-279, 1973.

Hedin, A. E., Extension of the MSIS thermosphere model into the middle and lower atmosphere, J. Geophys. Res., 96, 1159-1172, 1991.

Hunt, B. G., Photochemistry of ozone in a moist atmosphere, J. Geophys. Res., 71, 1385-1398, 1966

Jones, J., B. A. McIntosh, and M. Simek, Ozone and the duration of overdense radio meteors, J. Atmos. Terr. Phys., 52, 253-258, 1990.

Justus, C. G., W. R. Jeffries III, S. P. Yung, and D. L. Johnson, The NASA/ MSFC Global Reference Atmospheric Model-1995 Version (GRAM-95), NASA Tech. Memo., 4715, 1995.

Kaufmann, M., O. A. Gusev, K. U. Grossmann, R. Roble, M. Hagan, C. Hartsough, and A. A. Kutepov, The vertical and horizonal distribution of $\mathrm{CO}_{2}$ densities in the upper mesosphere and lower thermosphere as measured by CRISTA, J. Geophys. Res., 107(D23), 8182, doi:10.1029/2001JD000704, 2002.

Keneshea, T. J., S. P. Zimmerman, and C. R. Philbrick, A dynamic model of the mesosphere and lower thermosphere, Planet. Space Sci., 27, 385401,1979

Krueger, A. J., B. Guenther, A. J. Fleig, D. F. Health, E. Hilsenrath, R. C. McPeters, and C. Prabhakara, Satellite ozone measurements, Philos. Trans. R. Soc. London, Ser. A, 296, 194-204, 1980.

Kutepov, A. A., O. A. Gusev, and V. P. Ogibalov, Solution of the non-LTE problem for molecular gas in planetary atmospheres: Superiority of accelerated lambda iteration, J. Quant. Spectrosc. Radiat. Transfer, 60, 199-220, 1998.

Lary, D. J., Photochemical studies with a 3D model of the atmosphere, Ph.D. thesis, Cambridge Univ., Cambridge, England, 1991.

Livesey, N. J., W. G. Read, L. Froidevaux, J. W. Waters, M. L. Santee, H. C. Pumphrey, D. L. Wu, Z. Shippony, and R. F. Jarnot, The UARS Microwave Limb Sounder version 5 dataset: Theory, characterization and validation, J. Geophys. Res., 108, doi:10.1029/2002JD002273, in press, 2003.

Llewellyn, E. J., and G. Witt, The measurement of ozone concentrations at high latitudes during the twilight, Planet. Space Sci., 25, 165, 1977.

London, J., Radiative energy sources and sinks in the stratosphere and mesosphere, in Proceedings of the NATO Advanced Study Institute on Atmospheric Ozone: Its Variation and Human Influences, edited by M. Nicolet and A. C. Aikin, U.S. Dep. of Transp., p. 3144, Washington, D. C., 1980.

López-González, M. J., J. J. López-Moreno, and R. Rodrigo, Altitude profiles of the atmospheric system of $\mathrm{O}_{2}$ and of the green line emission, Planet. Space Sci., 40, 783-795, 1992a.

López-González, M. J., J. J. López-Moreno, and R. Rodrigo, The altitude profile of the infrared atmospheric system of $\mathrm{O}_{2}$ in twilight and early night: Derivation of ozone abundances, Planet. Space Sci., 40, $1391-$ 1397, 1992b.

Madronich, S., and S. Flocke, The role of solar radiation in atmospheric chemistry, in Handbook of Environmental Chemistry, edited by P. Boule, pp. 1-26, Springer-Verlag, New York, 1998.

Manuilova, R. O., and G. M. Shved, The 4.8 and $9.6 \mu \mathrm{m} \mathrm{O} 3$ band emissions in the middle atmosphere, J. Atmos. Terr. Phys., 54, 1149-1168, 1992.

Manuilova, R. O., et al., Modelling of non-LTE limb spectra of i.r. ozone bands for the MIPAS space experiment, J. Quant. Spectrosc. Radiat. Transfer, 59, 405-422, 1998.

Marsh, D. R., A. Smith, G. Brasseur, M. Kaufmann, and K. Grossmann, The existence of a tertiary ozone maximum in the high-latitude middle mesosphere, Geophys. Res. Lett., 28, 4531-4534, 2001.

Marsh, D. R., W. R. Skinner, A. R. Marshall, P. B. Hays, D. A. Ortland, and J.-H. Yee, High Resolution Doppler Imager observations of ozone in the mesosphere and lower thermosphere, J. Geophys. Res., 107(D19), 4390, doi:10.1029/2001JD001505, 2002.

Menard, J., L. Doyennette, and F. Menard-Bourcin, Vibrational relaxation in $\mathrm{O}_{3}, \mathrm{O}_{2}$ and $\mathrm{O}_{2}-\mathrm{N}_{2}$ gas mixtures from infrared double-resonance measurements in the $200-300 \mathrm{~K}$ temperature range, J. Chem. Phys., 96, $15,773-15,780,1992$

Mill, J. D., R. R. O’Neill, S. Price, G. J. Romick, O. M. Uy, E. M. Gaposchkin, G. C. Light, W. W. Moore Jr., T. L. Murdock, and A. T. Stairs Jr., Midcourse Space Experiment: Introduction to the spacecraft, instruments, and scientific objectives, Spacecraft, 31(5), 900-907, 1994.

Mlynczak, M. G., and S. R. Drayson, Calculation of infrared limb emission by ozone in the terrestrial middle atmosphere, 1, Source function, J. Geophys. Res., 95, 16,497-16,511, 1990a.

Mlynczak, M. G., and S. R. Drayson, Calculation of infrared limb emission by ozone in the terrestrial middle atmosphere, 2, Emission calculations, J. Geophys. Res., 95, 16,513-16,521, 1990b. 
Mlynczak, M. G., and D. K. Zhou, Kinetic and spectroscopic requirements for the measurement of mesospheric ozone at $9.6 \mu \mathrm{m}$ under non-LTE conditions, Geophys. Res. Lett., 25, 639-642, 1998.

Mlynczak, M. G., F. Morgan, and J.-H. Yee, Simultaneous measurements of the $\mathrm{O}_{2}\left({ }^{1} \Delta\right)$ and $\mathrm{O}_{2}\left({ }^{1} \Sigma\right)$ airglows and ozone in the daytime mesosphere, Geophys. Res. Lett., 28, 999-1002, 2001.

Noxon, J. F., Twilight enhancement in $\mathrm{O}_{2}\left(b^{1} \Sigma_{g}\right)$ airglow emission, J. Geophys. Res., 80, 1370-1373, 1975.

Offermann, D., K. U. Grossmann, P. Barthol, P. Knieling, M. Riese, and R. Trant, Cryogenic Infrared Spectrometers and Telescopes for the Atmosphere (CRISTA) experiment and middle atmosphere variability, J. Geophys. Res., 104, 16,311-16,325, 1999

Pemberton, D. N. C., Radiative emission from $\mathrm{O}_{3}$ and $\mathrm{HNO}_{3}$ in the middle atmosphere, Ph.D. thesis, Univ. of Oxford, Oxford, England, 1993.

Prather, M. J., Ozone in the upper stratosphere and mesosphere, J. Geophys. Res., 86, 5325-5338, 1981.

Rawlins, W. T., G. E. Caledonia, J. J. Gibson, and A. T. Stair Jr., HIRIS Rocketborne spectra of infrared fluorescence in the $\mathrm{O}_{3}\left(\mathrm{v}_{3}\right)$ band near 100 km, J. Geophys. Res., 90, 2896-2904, 1985.

Rawlins, W. T., G. E. Caledonia, and R. A. Armstrong, Dynamics of vibrationally excited ozone formed by three-body recombination: II. Kinetics and mechanism, J. Chem. Phys., 87, 5209-5221, 1987.

Riegler, G. R., J. F. Drake, S. C. Liu, and R. J. Cicerone, Stellar occultation measurements of atmospheric ozone and chlorine from OAO 3, J. Geophys. Res., 81, 4997-5001, 1976.

Riese, M., R. Spang, P. Preusse, M. Ern, M. Jarisch, D. Offermann, and K. U. Grossmann, Cryogenic Infrared Spectrometers and Telescopes for the Atmosphere (CRISTA) data processing and atmospheric temperature and trace gas retrieval, J. Geophys. Res., 104, 16,349-16,367, 1999.

Roble, R. G., and P. B. Hays, On determining the ozone number density distribution from OAO-2 stellar occultation measurements, Planet. Space Sci., 22, 1338-1340, 1974.

Rodrigo, R., J. S. Nisbet, and E. Battaner, The effect of horizontal winds upon the chemical composition of the lower thermosphere at high latitude, J. Geophys. Res., 86, 3501-3508, 1981.

Rodrigo, R., J. J. López-Moreno, M. López-Puertas, F. Moreno, and A. Molina, Neutral atmospheric composition beween 60 and $220 \mathrm{~km}$ : A theoretical model for mid-latitudes Planet, Space Sci., 34, 723-743, 1986.

Rose, K., and G. Brasseur, A three-dimensional model of chemically active trace species in the middle atmosphere during disturbed winter conditions, J. Geophys. Res., 94, 16,387-16,403, 1989.

Russell, J. M., III, and S. R. Drayson, The inference of atmospheric ozone using satellite horizon measurements in the $1024 \mathrm{~cm}^{-1}$ band, J. Atmos. Sci., 29, 376-390, 1972.

Rybicki, G. B., and D. G. Hummer, An accelerated lambda iteration method for multilevel radiative transfer, I, Non-overlapping lines with background continuum, Astron. Astrophys., 245, 171-181, 1991.

Shimazaki, T., and A. R. Laird, A model calculation of the diurnal variation in minor neutral constituents in the mesosphere and lower thermo- sphere including transport effects, J. Geophys. Res., 75, 3221-3235, 1970.

Solomon, S., J. T. Kiehl, B. J. Kerridge, E. E. Remsberg, and J. M. Russel III, Evidence for nonlocal thermodynamic equilibrium in the $\nu_{3}$ mode of mesospheric ozone, J. Geophys. Res., 91, 9865-9876, 1986.

Steinfeld, J. I., S. M. Adler-Golden, and J. W. Gallagher, Critical survey of data on the spectroscopy and kinetics of ozone in the mesosphere and thermosphere, J. Phys. Chem. Ref. Data, 16, 911-941, 1987.

Thomas, R. J., Atomic hydrogen and atomic oxygen density in the mesopause region: Global and seasonal variations deduced from solar mesosphere explorer near-infrared emissions, J. Geophys. Res., 95, 16,457-16,476, 1990.

Thomas, R. J., C. A. Barth, D. W. Rusch, and R. W. Sanders, Solar mesosphere explorer near-infrared spectrometer: Measurements of 1.27- $\mu \mathrm{m}$ radiances and the inference of mesospheric ozone, J. Geophys. Res., 89, 9569-9580, 1984.

Trinks, H., Ozone measurements between 90 and $110 \mathrm{~km}$ altitude by mass spectrometer, Geophys. Res. Lett., 2, 99-102, 1975.

Weeks, L. H., R. E. Good, J. S. Randhawa, and H. Trinks, Ozone measurements in the stratosphere, mesosphere, and lower thermosphere during Aladdin 74, J. Geophys. Res., 83, 978-982, 1978.

West, G. A., R. E. Weston Jr., and G. W. Flynn, The influence of reactant vibrational excitation on the $\left.\mathrm{O}^{3} P\right)+\mathrm{O}_{3}$ bimolecular reaction rate, Chem. Phys. Lett., 56, 429-433, 1978.

Wilson, W. J., and P. R. Schwartz, Diurnal variations of mesospheric ozone using millimeter-wave measurements, J. Geophys. Res., 86, 7385-7388, 1981.

Zhou, D. K., M. G. Mlynczak, G. E. Bingham, J. O. Wise, and R. M. Nadile, CIRRIS-1A limb spectral measurements of mesopheric $9.6 \mu \mathrm{m}$ airglow and ozone, Geophys. Res. Lett., 25, 643-646, 1998.

Zommerfelds, W. C., K. F. Kunzi, M. E. Summers, R. M. Bevilacqua, D. F. Strobel, M. Allen, and W. J. Sawchuck, Diurnal variations of mesospheric ozone obtained by ground-based microwave radiometry, J. Geophys. Res., 94, 12,819-12,832, 1989.

K. U. Grossmann and O. A. Gusev, Department of Physics, University of Wuppertal, 42281 Wuppertal, Germany. (gross@wpos2.physik.uniwuppertal.de; oleg@crista.uni-wuppertal.de)

M. Kaufmann, Research Center Jülich, ICG-I, 52425 Jülich, Germany. (kaufmann@uni-wuppertal.de)

A. A. Kutepov, MPI for Extraterrestrial Physics/Institute for Astronomy and Astrophysics, University of Munich,81679 München, Germany. (aak@ usm.uni-muenchen.de)

D. R. Marsh, National Center for Atmospheric Research, P. O. Box 3000, Boulder, CO 80307 USA. (marsh@ucar.edu)

F. J. Martín-Torres, Analytical Services and Materials, Inc., NASA Langley Research Center, 107 Research Drive, Hampton, VA, USA. (f.martin-torres@larc.nasa.gov) 